\title{
Integrated approach for the prediction of crack width and spacing in flexural FRC members with hybrid reinforcement
}

\author{
Mahsa Taheri $^{\mathrm{a}, *}$, Joaquim A.O. Barros ${ }^{\mathrm{b}}$, Hamidreza Salehian ${ }^{\mathrm{c}}$ \\ ${ }^{a}$ ISISE, Department of Civil Engineering, University of Minho, Guimarães, Portugal \\ ${ }^{\mathrm{b}}$ ISISE, Institute of Science and Innovation for Bio-Sustainability (IB-S), Department of Civil Engineering, University of Minho, Guimarães, Portugal \\ ${ }^{\mathrm{c}}$ Seismic Geotechnical and High Performance Concrete Research Centre, Department of Civil Engineering, Semnan Branch, Islamic Azad University, Semnan, Iran
}

\section{A R T I C L E I N F O}

\section{Keywords:}

Fibre reinforced concrete

Hybrid flexural reinforcement

Bond model

Crack width

Crack spacing

\begin{abstract}
A B S T R A C T
In this paper, a new model is developed based on the moment-rotation approach to predict average crack width and average crack spacing of flexural elements made of fibre reinforced concrete (FRC) that also include longitudinal steel and/or fibre reinforced polymer (FRP) bars. The post-cracking behaviour of FRC is simulated by a stress-crack width relationship, while the interaction between concrete and longitudinal reinforcement is modelled by a multilinear shear stress-sliding diagram based on experimental evidence. For assessing the predictive performance of the developed model, an experimental program was executed with this type of structural elements, where the moment versus average crack width and crack spacing were recorded. The good predictive performance of the model was also demonstrated by using experimental results available in the literature. The predictive performance was, in general, better than the predictions from RILEM TC 162-TDF and fib Model Code 2010 .
\end{abstract}

\section{Introduction}

Cracking in concrete is one of the main crucial aspects threaten the durability and structural performance of reinforced concrete (RC) structures. This problem is much more pronounced in case of steel reinforced concrete (S/RC) structural elements, since they are often subjected to tensile stress fields. The stiffness and load carrying capacity of RC elements decrease with the formation and propagation of cracks, which can compromise their design requisites at serviceability and ultimate limit state conditions (SLS and ULS, respectively). Crack propagation in S/RC elements also increases the permeability of concrete, facilitating the ingress of environmental adverse agents through the concrete zones where steel reinforcement is disposed, which promotes its corrosion as faster as wider are the cracks [1]. This generally results in a reduction of the cross-section area of the steel reinforcement, deterioration of steel-to-concrete bond quality, and concrete spalling and disintegration, which are all responsible for a reduction of load carrying capacity of structural S/RC elements.

Substitution of steel reinforcements by non-corrodible ones made of fibre reinforced polymer (FRP) has been investigated during the last decades, in an attempt of improving the durability of RC structural elements $[2,3]$. Hereinafter these elements will be designated by the acronym F/RC to distinguish them from those reinforced with steel bars
(S/RC). The use of FRP as internal reinforcement of concrete structures may have, however, some detrimental consequences in structural design viewpoint. When compared to steel, the commonly used and costcompetitive FRPs have lower elasticity modulus and bond performance to concrete, and their properties are detrimentally affected by high temperatures. These aspects often lead to a larger deflection and wider cracks in F/RC elements subjected to flexural loading conditions, such is the case of beams and slabs, so accomplishing the design requisites at SLS of F/RC are often predominant [4,5]. Furthermore, due to the larger crack width, the shear capacity of F/RC beams is smaller than S/ $\mathrm{RC}$ beams of the same reinforcement ratio due to its detrimental impact on the aggregate interlock resisting mechanism [6]. The previously pointed out drawbacks can be mitigated by adopting hybrid flexural reinforcement (HFR), where FRP bars are placed with the minimum possible concrete cover thickness in order to take advantage of their immunity to corrosion, while steel bars are disposed with higher concrete cover thickness for being better protected from corrosion agents [7]. Elements with HFR are hereinafter abbreviated by the acronym $\mathrm{H} /$ RC, where the high tensile strength of FRPs can be combined with the elasto-plastic behaviour of steel reinforcements for ensuring adequate performance at SLS and ULS design conditions. Experimental evidences revealed that the deflection, crack width, and crack spacing of $\mathrm{H} / \mathrm{RC}$ beams are generally smaller than that of F/RC beams, and failure mode

\footnotetext{
* Corresponding author.

E-mail addresses: taheri.mahsa09@gmail.com (M. Taheri), barros@civil.uminho.pt (J.A.O. Barros), hrsalehian@semnaniau.ac.ir (H. Salehian).
} 
can be more ductile $[7,8]$. The potentialities of HFR can be increased when used with fibre reinforced concrete (FRC) for the development of hybrid flexurally reinforced FRC (H/FRC) beams [9]. When cracks are formed in concrete, the discrete fibres bridging these cracks offer resistance to their widening by fibre pull-out mechanisms $[9,10]$, leading to significant benefits in terms of SLS and ULS design requisites and on the durability regarding the ones of S/RC, F/RC and H/RC elements. According to Wang and Belarbi [2], an improvement of $30 \%$ of durability index of RC beams was achieved by the addition of $0.5 \%$ volume fraction of fibres. The influence of fibres for minimising the occurrence of shear cracks and increasing the shear resistance of FRC beams is noticeable [11-13]. It has been demonstrated that in shallow reinforced FRC (R/FRC) beams, steel stirrups can be replaced by fibres with technical and economic advantages [14]. Discrete fibres have also contributed to reduce the deflection of R/RC beams under service loads, and to increase the maximum load carrying capacity $[15,16]$. Experimental and numerical investigations have revealed that the favourable fibre reinforcement mechanisms on the post-cracking behaviour of concrete have effectively improved the tension-stiffening effect due to stress transference between flexural reinforcements and surrounding concrete during the concrete cracking process $[17,18]$, resulting in reduction in the width and spacing of cracks [19-21], as well as in maximum stress level in the flexural reinforcement [22].

In the present paper is developed an integrated approach for the prediction of crack width and spacing in H/FRC flexural elements, where mechanical properties of intervening materials, the post-cracking response of FRC in terms of stress-crack opening relationship $(\sigma-w)$, and the shear bond-sliding characteristics of steel- and FRP-to-concrete interaction, are mobilised in a model developed based on moment-rotation approach [23]. The predictive performance of the proposed approach is evaluated by using the results from an experimental program conducted for this purpose, as well as the ones available in the literature [24-26]. The predictive performance in terms of crack width and spacing of the formulations proposed by two international organizations $[27,28]$ is also assessed and commented.

\section{Model developed based on the moment-rotation approach}

Fig. 1a depicts an idealised crack pattern in a pure bending region (PBR) of $L_{P B R}$ length of an R/FRC element subjected to bending moment $(M)$ and consequent overall rotation $(\theta)$. It is assumed that the geometry of the beam's cross-section and reinforcing scheme of the section is constant along the $L_{P B R}$. The considered R/FRC element is assumed to have a symmetric cross-section as shown in Fig. 1b, where the width can vary along its depth, $h$. The total height of the cross-section is decomposed in $n$ layers to take into account the appropriate constitutive law for each material layer during the loading procedure.
The width, the thickness and the depth of the generic $i^{\text {th }}$ layer (numbered from the beam's top surface) are represented by $b_{i}, t_{i}$, and $d_{i}$, respectively. The $i^{\text {th }}$ layer may also include reinforcing bars of total cross-sectional area $A_{r i}$. In this case, the total width of the layer $\left(b_{i}\right)$ is subdivided into the equivalent width of reinforcement $b_{r i}\left(=A_{r i} / t_{i}\right)$ and the width of concrete $b_{c}\left(=b_{i}-b_{r i}\right)$ (see Fig. 1b). By progressively increasing the applied bending moment, the most tensioned concrete surface (in Fig. 1a is the bottom surface) attains the concrete strain at crack initiation $\left(\varepsilon_{c t}=\varepsilon_{c r}\right)$ and, consequently, several flexural cracks may propagate along the PBR, subdividing the $L_{P B R}$ into several R/FRC prisms of $L_{c s}$ length. Therefore, in each step of loading $L_{c s}$ is representative of spacing between two adjacent cracks. At cracking stabilised stage, i.e., no new more cracks are formed, the minimum value of $L_{c s}$ is considered the average crack spacing, $s_{r m}$, at this stage.

Due to the constant bending moment and equal geometry and reinforcing scheme of the beam's cross-section along the PBR, the cracks geometry (i.e. the width and depth) and spacing are assumed the same.

\subsection{Mechanical properties of intervening materials}

\subsubsection{Compressive behaviour of FRC}

The compressive behaviour of FRC can be subdivided into the prepeak and the post-peak responses. Imposing strains lower than the one corresponding to the concrete compressive strength $\left(\varepsilon_{c c, p}\right.$, Fig. 2), only small isolated and randomly distributed cracks are formed, therefore the continuous nature of concrete can be assumed valid. When $\varepsilon_{c c, p}$ is exceeded, internal microcracks coalesce into macro-cracks leading to crack localisation. Consequently, the use of strain as a state variable in constitutive laws for compressive concrete is not valid anymore. [29]. In this case, the post-peak behaviour of concrete in compression can be analysed by the wedge sliding mechanism [30]. However, since the present research is aiming to analyse the behaviour of R/FRC flexural beams during the cracking propagation stage, by estimating the crack width and average crack spacing for serviceability limit state design conditions, the maximum concrete compressive strain level is less than $\varepsilon_{c c, p}$. Therefore, and for the sake of simplicity, the stress-strain relationship $\left(\sigma_{c c}-\varepsilon_{c c}\right)$ schematised in Fig. 2 was adopted for simulating the concrete compression behaviour, which is represented by the following equations [31]:

$$
\begin{aligned}
& \sigma_{c c}\left(\varepsilon_{c c}\right)=f_{c c} \frac{\varepsilon_{c c} / \varepsilon_{c c, p}}{(1-p-q)+q\left(\varepsilon_{c c} / \varepsilon_{c c, p}\right)+p\left(\varepsilon_{c c} / \varepsilon_{c c, p}\right)^{\frac{1-q}{p}}} \\
& \left.q=1-p-\frac{E_{c, \mathrm{sec}}}{E_{c}}, p+q \in\right] 0,1\left[, \frac{1-q}{p}>0\right.
\end{aligned}
$$

where $\varepsilon_{c c, p}$ is the strain corresponding to the concrete compressive strength $\left(f_{c c}\right), E_{c, s e c}$ is the secant modulus of elasticity of concrete

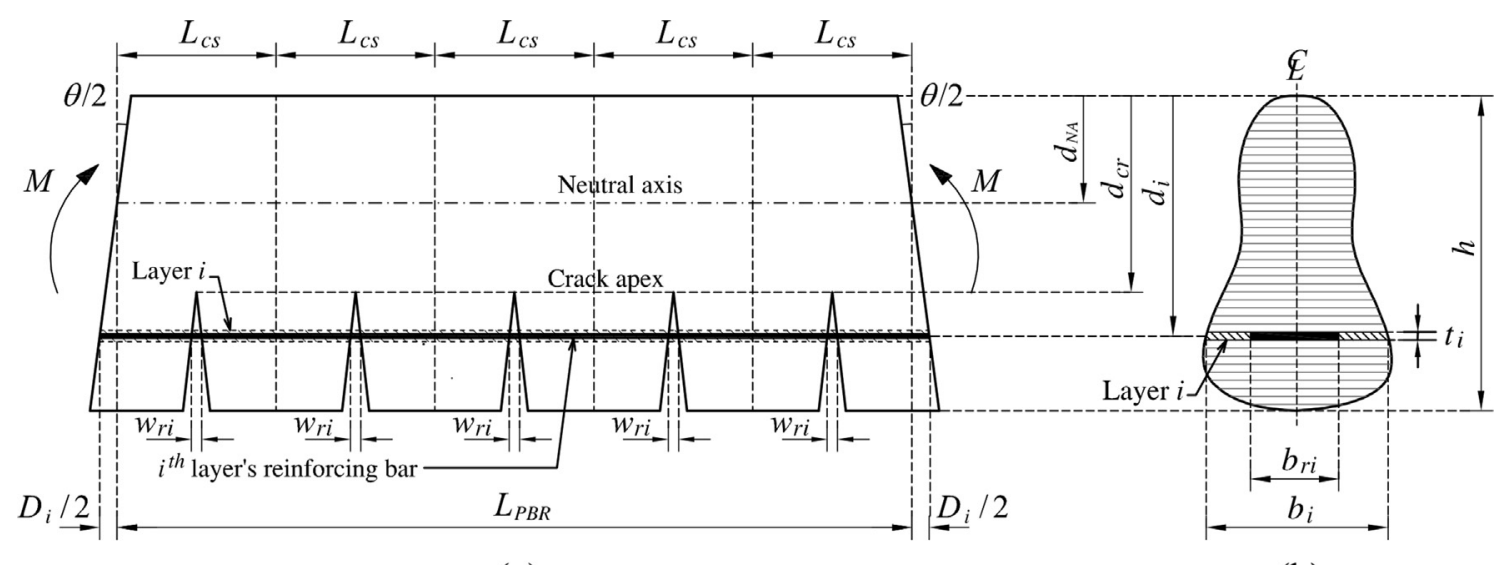

(a)

(b)

Fig. 1. (a) Cracking propagation in a pure bending region of R/FRC beams, (b) layer approach to model the cross-section. 


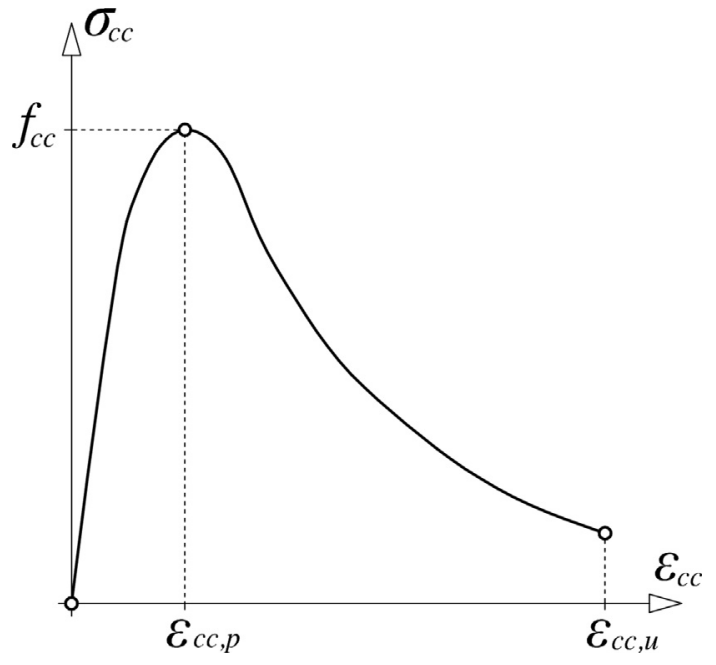

Fig 2. Stress-strain diagram for simulating the compressive behaviour of an FRC.

$\left(=f_{c c} / \varepsilon_{c c, p}\right)$, and $p$ is a parameter ranging between 0 and 1 . For concrete reinforced with hooked ends steel fibres the following equations were adopted for determining $\varepsilon_{c c, p}$ and $p$ parameters [32]:

$\varepsilon_{c c, p}^{S F R C}=\varepsilon_{c c, p}^{P C}+0.000654 V_{f}$

$p=1.0-0.919 \exp \left(-1.289 V_{f}\right)$

where $V_{f}$ is the fibre volume percentage, and $\varepsilon_{c c, p}^{P C}$ is the strain at the compressive strength of the plain concrete of the same strength class of the FRC [27]. The superscript SFRC and PC in Eq. (3) indicates that the entity is measured in specimens of steel fibre reinforced concrete and plain concrete of the same strength class, respectively. For concrete reinforced with fibres other than of steel material, specific equations for the $\varepsilon_{c c, p}$ and $p$ should be derived based on experimental results with the FRC.

\subsubsection{Tensile behaviour of FRC}

The constitutive law adopted to simulate the tensile behaviour of FRC is shown in Fig. 3 which comprises a bilinear pre-cracking stressstrain relationship (Fig. 3a) and a multi-linear post-cracking constitutive law represented by stress-crack width relationship (Fig. 3b). The adopted tensile constitutive law enables the model to simulate FRC of both strain softening and strain hardening nature (SS-FRC and SHFRC, respectively). In case of SS-FRC, after crack initiation, at $\left(\varepsilon_{c r}, f_{c t}\right)$, the tensile behaviour is governed by a stress-crack width relationship of
Fig. 3b. Therefore the second branch of the stress-strain diagram of Fig. 3a is almost inexistent, i.e., $\varepsilon_{c t, p}=\varepsilon_{c r}$ and $\sigma_{c t, p}=f_{c t}$. In the case of SH-FRC, after crack initiation, several cracks are progressively formed up to the degeneration of one of these cracks into a macro-crack. This stage is simulated by the second branch of the $\sigma_{c t}-\varepsilon_{c t}$ relationship, whose stiffness depends on the reinforcement mechanisms developed between fibres and the surrounding matrix.

The stress-strain diagram is simulated by the following equations (Fig. 3):

$\sigma_{c t}\left(\varepsilon_{c t}\right)==\left\{\begin{array}{lrl}E_{c} \varepsilon_{c t} & 0 \leqslant \varepsilon_{c t} \leqslant \varepsilon_{c r} & \text { (a) } \\ f_{c t}+\left(\frac{\varepsilon_{c t}-\varepsilon_{c r}}{\varepsilon_{c t, p}-\varepsilon_{c r}}\right)\left(\sigma_{c t, p}-f_{c t}\right) & \varepsilon_{c r}<\varepsilon_{c t} \leqslant \varepsilon_{c t, p} & \text { (b) }\end{array}\right.$

where $\varepsilon_{c r}=f_{c t} / E_{c}$ is the strain at crack initiation, and $f_{c t}$ and $E_{c}$ are the tensile strength and Young's modulus of FRC that can be obtained from the recommendations of fib Model Code 2010 [27]:

$f_{c t}= \begin{cases}0.30 f_{c k}^{2 / 3} & {[\text { for concrete strength class } \leqslant C 50 / 60]} \\ 2.12 \ln \left(1+f_{c m} / 10\right) & {[\text { for concrete strength class }>C 50 / 60]}\end{cases}$

$E_{c}=21.5\left(\frac{f_{c m}}{10}\right)^{1 / 3}\left[f_{c m}\right.$ in $\mathrm{MPa}, E_{c}$ in $\left.\mathrm{GPa}\right]$

being $f_{c k}$ and $f_{c m}$ the characteristic and average value of compressive strength of concrete, respectively. In Eq. (5b) $\sigma_{c t, p}$ and $\varepsilon_{c t, p}$ are the tensile strength and corresponding strain of SH-FRC, respectively. Macrocracking propagation is described by a stress-crack opening diagram that can be formed by multi-linear segments (Fig. 3b) to have the potential of capturing, with high accuracy, the behaviour of the softening response of cement-based materials reinforced with mono- or hybrid fibre systems [33]:

$$
\begin{array}{r}
\sigma_{c t}(w)=\left[\alpha_{i}+\left(\alpha_{i+1}-\alpha_{i}\right) \frac{w-w_{i}}{w_{i+1}-w_{i}}\right] \sigma_{c t, p} \quad\left(\text { for } w_{i} \leqslant w \leqslant w_{i+1}\right) \\
\left(i=0 \text { to } 6, \alpha_{0}=1, w_{0}=0, \alpha_{6}=0, w_{6}=w_{u}\right)
\end{array}
$$

where $\alpha_{i}=\sigma_{i} / f_{c t}$ is the normalised stress parameter corresponding to crack width $w_{i}$, and $w_{u}$ is the ultimate crack width. The shape of the $\sigma-w$ diagram is generally determined by performing uniaxial tensile tests with notched FRC specimens $[34,35]$, or by inverse analysis by fitting with a target accuracy the force-deflection registered in notched FRC beam bending tests $[36,37]$.

\subsubsection{Behaviour of longitudinal reinforcing bars}

The bilinear stress-strain relationship represented in Fig. 4 is adopted for the longitudinal reinforcement in both compression and

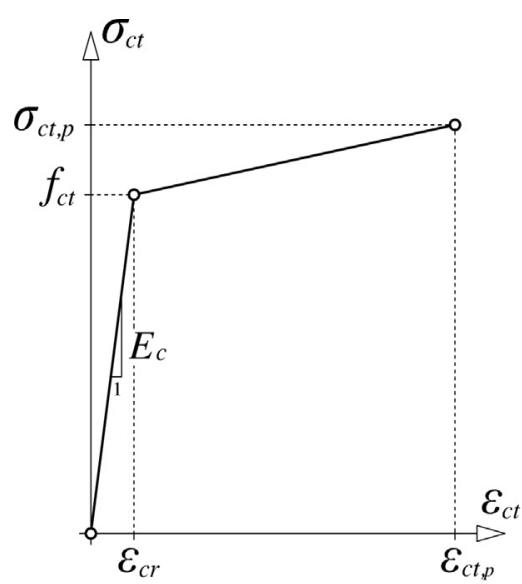

(a)

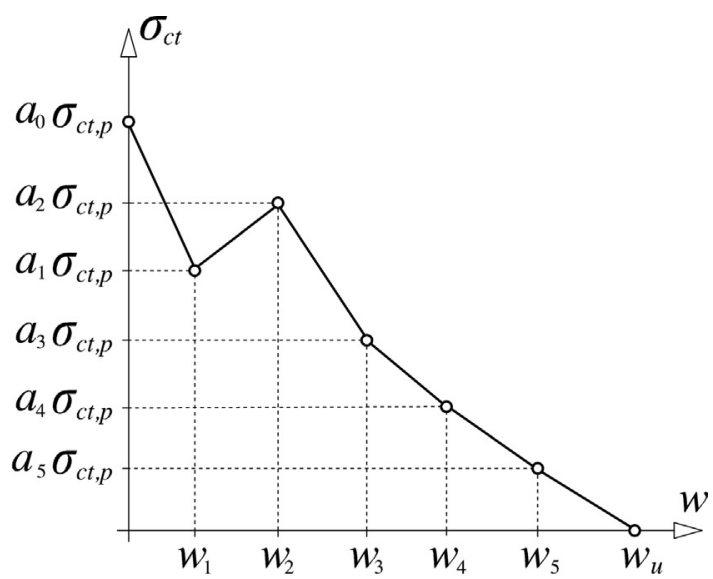

(b)

Fig. 3. Tensile behaviour of FRC: (a) stress-strain diagram before macro-cracking localization, (b) post-cracking stress-crack width response. 


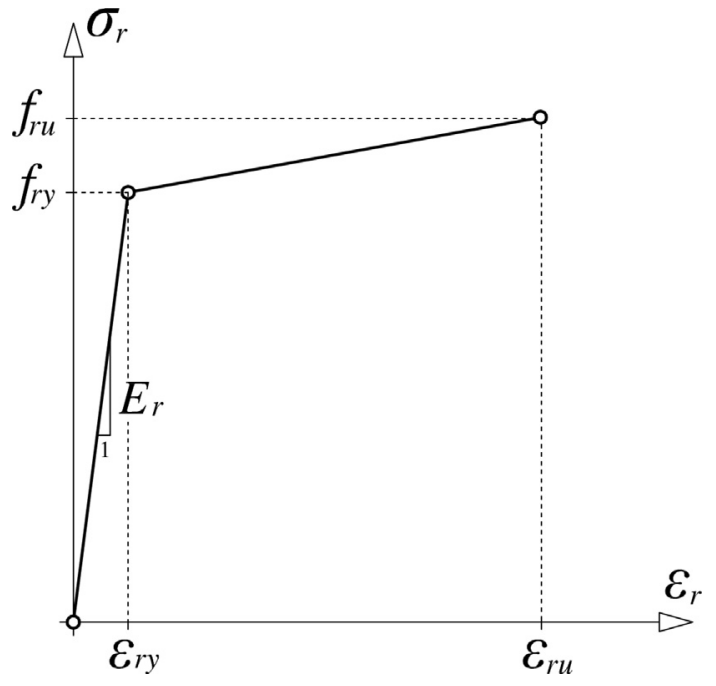

Fig. 4. Stress-strain relationship for simulating the tension and compression behaviour of longitudinal reinforcements.

tension that can be described by the following equation:

$\sigma_{r}\left(\varepsilon_{r}\right)=\left\{\begin{array}{lcl}E_{r} \varepsilon_{r} & \varepsilon_{r} \leqslant \varepsilon_{r y} & \text { (a) } \\ f_{r y}+\left(\varepsilon_{r}-\varepsilon_{r y}\right)\left(\frac{f_{r u}-f_{r y}}{\varepsilon_{r u}-\varepsilon_{r y}}\right) & \varepsilon_{r y}<\varepsilon_{r} \leqslant \varepsilon_{r u} & \text { (b) }\end{array}\right.$

where $E_{r}, f_{r y}$, and $f_{r u}$ are, respectively, the modulus of elasticity, the yielding stress, and ultimate strength of the reinforcement, while $\varepsilon_{r y}$ and $\varepsilon_{r u}$ are the strains corresponding to $f_{r y}$ and $f_{r u}$, respectively. The constitutive law of Fig. 4 can also simulate reinforcement of elastic-perfectly plastic behaviour, such is the case of some steel bars, by considering the same value for $f_{r y}$ and $f_{r u}$. This diagram is also adaptable for simulating the behaviour of FRP bars since their linear-brittle nature can be model by assuming $\varepsilon_{r u}=\varepsilon_{r y}$ and $f_{r u}=f_{r y}$.

\subsection{FRC-to-longitudinal reinforcement interaction}

\subsubsection{Local bond stress-slip relationship}

In the developed model, the multi-linear shear bond stress-slip relationship $(\tau-s)$ represented in Fig. 5 is adopted for simulating the bond mechanisms between longitudinal reinforcements and surrounding FRC. The adopted configuration for the $\tau-s$ is sufficiently

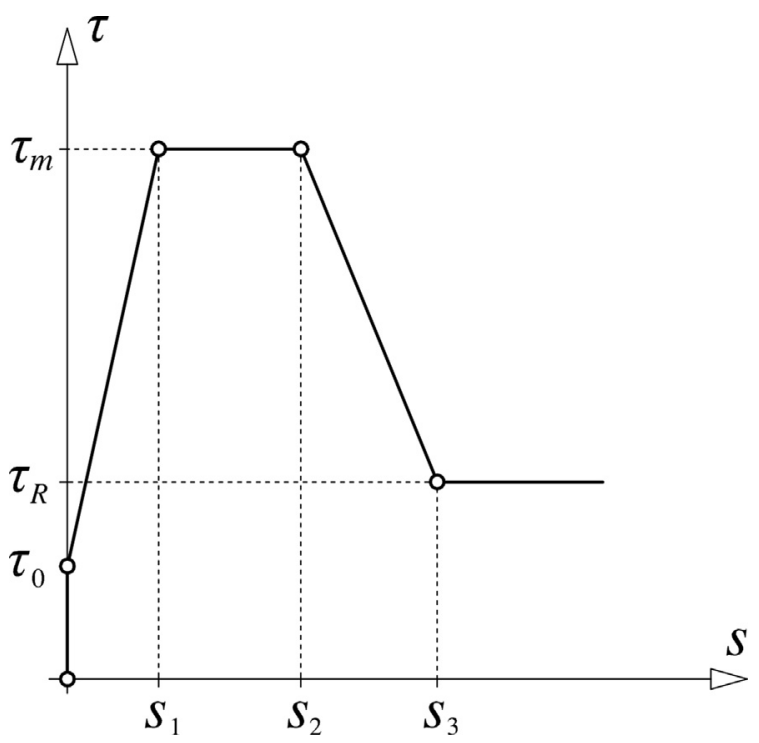

Fig. 5. Shear bond stress-slip relationship for embedded reinforcement. flexible for simulating the bond conditions of FRP bars [38] and steel bars [39]. This model is based on the one originally developed by Eligehausen et al. [40] to describe the local bond stress-slip behaviour of deformed bars, as recommended in [27], with the difference of replacing the pre-peak parabolic curve by a linear bond-slip relationship in order to simplify the numerical approach.

$$
\begin{aligned}
& \tau(s(x)) \\
& =\left\{\begin{array}{rrrr}
\tau_{0}+\left(\frac{\tau_{m}-\tau_{0}}{s_{1}}\right) s(x) & 0 \leqslant s(x) \leqslant s_{1} & \text { (elastic phase) } \quad \text { (a) } \\
\tau_{m} & s_{1}<s(x) \leqslant s_{2} & \text { (plastic phase) } \quad \text { (b) } \\
& \tau_{m}-\left(\frac{\tau_{m}-\tau_{R}}{s_{3}-s_{2}}\right) & s_{2}<s(x) \leqslant s_{3} & \text { (softening phase) } \quad \text { (c) } \\
& {\left[s(x)-s_{2}\right]} & & \\
\tau_{R} & & s_{3}<s(x) & \text { (frictional phase) } \quad \text { (d) }
\end{array}\right.
\end{aligned}
$$

The adopted shear bond stress-slip relationship includes five different phases; 1) an adhesion stage with a bond strength of $\tau_{0}$ for null sliding; 2) a linear-elastic response up to attain the slip $s_{1}$ that corresponds to the occurrence of the shear bond strength $\left(\tau_{m}\right) ; 3$ ) a perfectly plastic slipping stage up to the slip $s_{2}$ where bond stress remains constant; 4) a slipping softening phase up to $s_{3}$; 5) a frictional phase where a constant residual bond stress $\left(\tau_{R}\right)$ is considered due to frictional mechanisms between reinforcing bar and surrounding concrete. A similar model was adopted by Bianco et al. [41] to simulate the bond-sliding response of carbon FRP (CFRP) laminates used in shear strengthening of RC beams by near surface mounted (NSM) technique, with a difference that the plastic phase was not considered.

2.2.2. Bond interaction between flexural reinforcement and surrounding $F R C$ in the cracking process of a R/FRC element

In Fig. 6a, a longitudinal bar of relatively large embedment length is crossed by a crack at one extremity (Section 1). Slip of the bar in Section 1 can be assumed equal to half the crack width at the level of this $\operatorname{bar}\left(s_{r}=w_{r} / 2\right)$, while it tends to be zero at the other extremity with perfect bond (Section 2) located at a distance $L_{t r}(s)$ from the crack face (Section 1).

In Fig. 6a, the internal force of the reinforcing bar and the surrounding concrete at Sections 1 and 2 are designated, respectively, by $\left(F_{r 1}, F_{c t 1}\right)$ and $\left(F_{r 2}, F_{c t 2}\right)$. Note that $F_{c t 1}$ and $F_{c t 2}$ can be determined considering the constitutive law of concrete in tension, according to the diagram represented in Fig. 3. In Fig. $6 \mathrm{~b}$ is depicted the force equilibrium of reinforcement and surrounding concrete along a finite bond transference length $d x$ for which, by satisfying equilibrium between tensile forces, the bond-sliding correlation along the interaction length can be represented by the following differential equation:

$\frac{d^{2} s(x)}{d x^{2}}-J_{1} \tau(x)=0$

where $J_{1}$ is a coefficient related to the geometry and modulus of elasticity of reinforcing bar and surrounding concrete:

$J_{1}=\left(\frac{L_{p}}{E_{r} A_{r}}+\frac{L_{p}}{E_{c} A_{c}}\right)$

being $A_{r}$ and $L_{p}$ the cross-sectional area and perimeter of the reinforcement bar, respectively. $A_{c}\left(=b \times c_{\text {eff }}\right)$ is also the effective area of tensile concrete surrounding the bar obtained by following the recommendations of fib Model Code 2010 [27]:

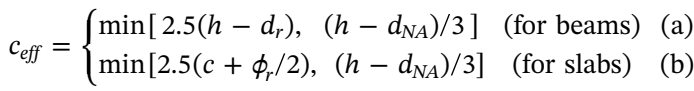

being $\phi_{r}$ the diameter of reinforcing bar, $c$ the concrete cover thickness, and $d_{r}$ the depth of the reinforcement.

The distance between cracked section (Section 1) and the nearest section with zero sliding (Section 2) in Fig. 6a gives the total bond 


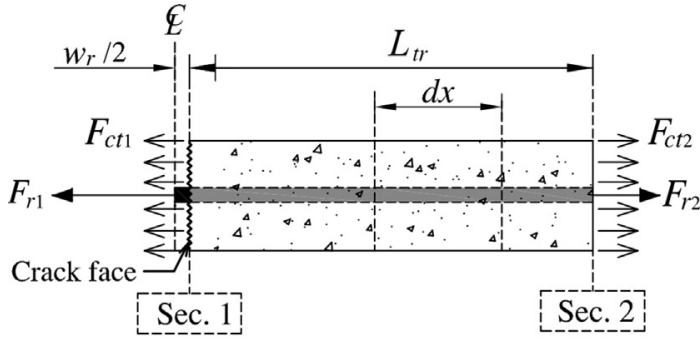

(a)

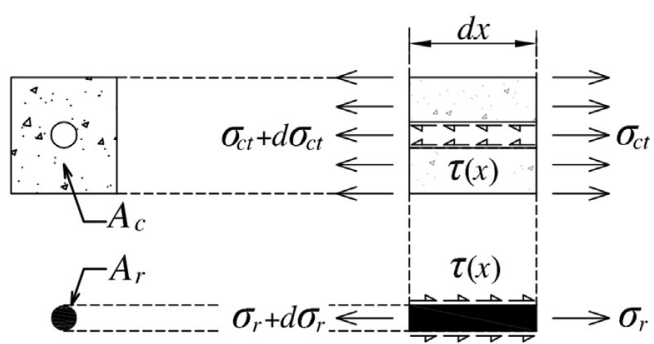

(b)

Fig. 6. (a) Reinforcing bar and surrounding concrete, (b) force equilibrium of reinforcement and surrounding concrete along an infinitesimal bond transference length of $d x$.

transference length designated by $L_{t r}(s)$ and obtained by solving the following differential equation:

$$
\frac{d s(x)}{d x}=\frac{(n+1)}{E_{r} A_{r}} \int_{0}^{L_{t r}} \tau(s(x)) L_{p} d x
$$

where $n=E_{r} A_{r} / E_{c} A_{c}$ is the axial stiffness ratio between reinforcement and surrounding concrete. In Table 1, the total bond transference length is formulated for the different considered phases of the bond-slip relationship (Fig. 5). In this Table is also included equations to determine the total load transmitted along the interaction length $\left(F_{\text {bond }}\right)$ determined by the following equation:

$F_{\text {bond }}=\int_{0}^{L_{t r}} \tau(s(x)) L_{p} d x$

By satisfying force equilibrium, the internal force of the reinforcement at the localised crack $\left(F_{r 1}\right.$ in Fig. $\left.6 a\right)$ is determined from the following equation:

$F_{r 1}=n F_{c t 1}+(n+1) F_{b o n d}$

where $F_{c t 1}=\sigma_{c t}\left(w_{r}=2 s_{\text {sec. } 1}\right) A_{c}$ is the tensile contribution of fibre reinforced concrete at cracked section. Furthermore, the internal force of reinforcing bar at Section 2 can be determined from Eq. (17):

$F_{r 2}=F_{r 1}-\int_{0}^{L_{t r}} \tau(s(x)) L_{p} d x$

\subsubsection{Order of formation and spacing of cracks in flexural elements}

In Fig. 7 is depicted a flexural R/FRC beam subjected to four-point bending load configuration. It is assumed this type of elements has sufficient shear reinforcement in the critical shear zones in order do not fail in shear. This can be done by contribution of conventional shear reinforcement or/and fibre reinforcement [42-44].

In the proposed model, the moment-rotation relationship [23,30] is used to determine the crack profile in the cross-section for the applied moment, from which the crack opening evolution is evaluated as well as the slip and the internal forces in the reinforcements according to the adopted bond-slip approach. Considering the overall rotation $(\theta)$ prescribed to the extremities of the PBR of $L_{P B R}$ length (see Fig. 1), the deformation of a generic $i^{\text {th }}$ layer $\left(D_{i}\right)$ and the corresponding effective strain $\left(\varepsilon_{e f, i}=D_{i} / L_{P B R}\right)$ is determined. For the layer positioned at the level of reinforcing bars, hereafter designated by Rlayer, the strain, $\varepsilon_{e f, r}$, is compared to the cracking strain of FRC $\left(\varepsilon_{c r}\right)$ (see Fig. 3a), and the

Table 1

Sliding, bond transference length, and total bond force determined for the various phases of bond-slip relationship.

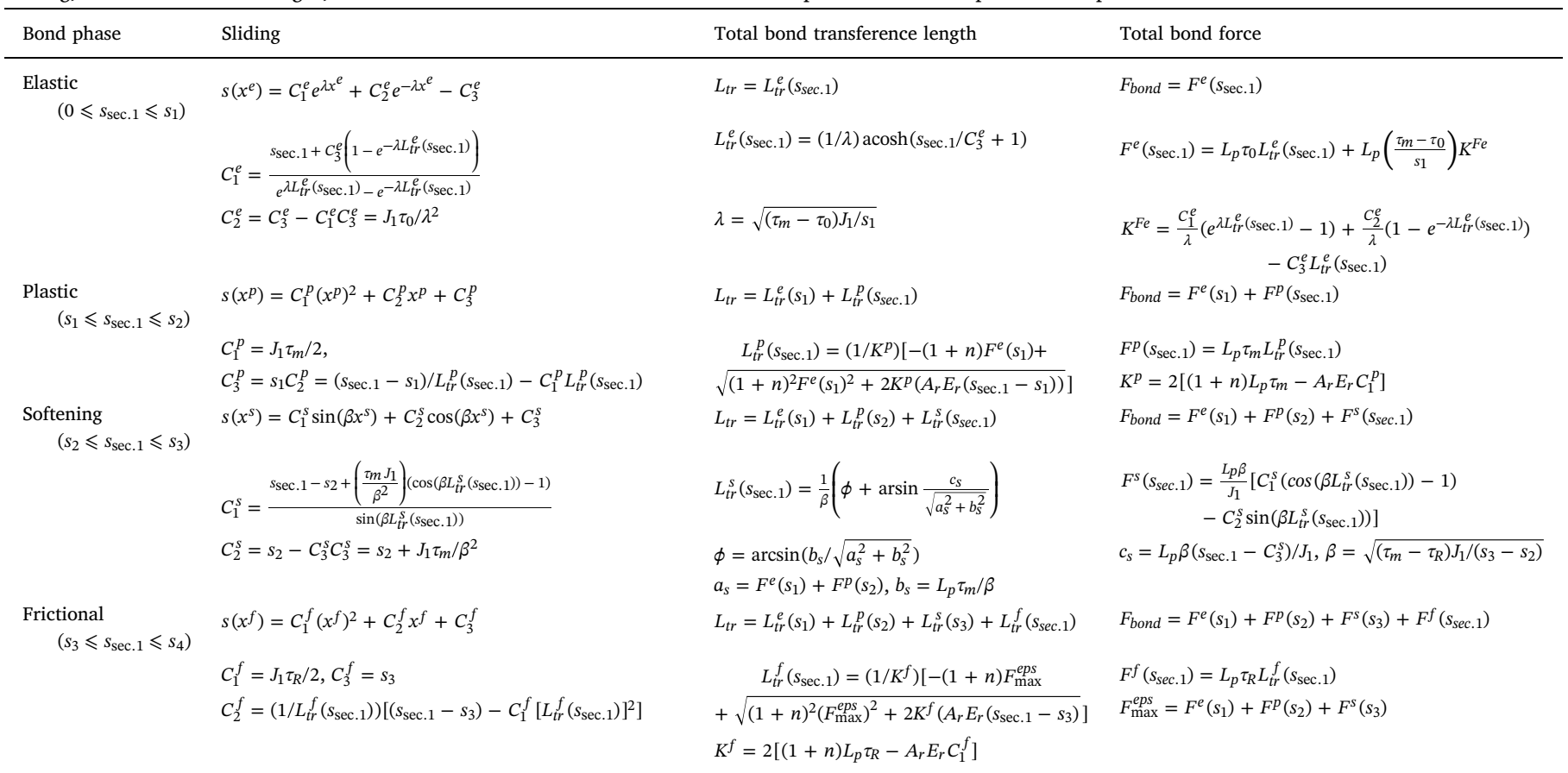




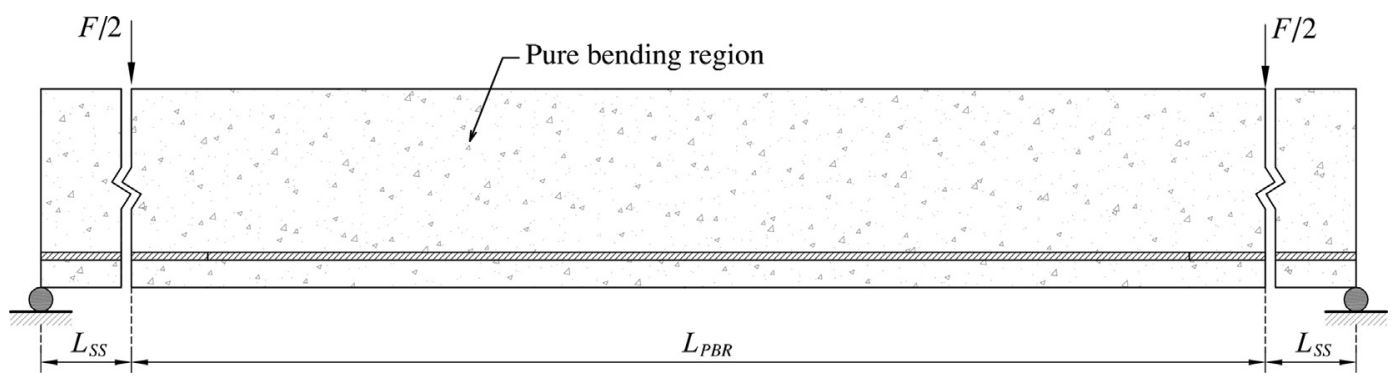

Fig. 7. Reinforced concrete beam subjected to four-point bending load configuration.

analysis should proceed according to the following possible scenarios.

2.2.3.1. Pre-cracking stage. As long as $\varepsilon_{e f, r}$ is smaller than $\varepsilon_{c r}$, the Rlayer does not crack. Consequently, the entire PBR is considered as an intact prism. In this case, interaction between concrete and embedded bar is considered as ruled by perfect bond conditions. Hence, the internal force of the bar $\left(F_{r}\right)$ is equal to the force originated by the strain of the reinforcement, designated herein by $F_{r, \sigma-\varepsilon}$, which is determined by multiplying the cross-sectional area of the reinforcing bars $\left(A_{r}\right)$ to the stress corresponding to $\varepsilon_{e f, r}$, i.e. $\sigma_{r}\left(\varepsilon_{e f, r}\right)$, according to the stress-strain constitutive law depicted in Fig. 4.

2.2.3.2. Cracking propagation stage. For a certain value of rotation imposed to the extremities of the PBR, $\varepsilon_{e f, r}$ becomes equal to $\varepsilon_{c r}$, representing the load configuration to the initiation of the first crack at Rlayer. Due to the disorder nature of concrete when regarded at microand meso-level because of the presence of micro- and meso-defects, in reality the first crack may occur at the most pronounced defects in the PBR. Nevertheless, for the convenience of simulation, in the proposed model it is assumed that the first crack forms at mid-span of the PBR (Fig. 8a). In this case, $F_{r}=F_{r, \sigma-\varepsilon}$ is kept as $F_{r, c r}$, which is the internal force of the reinforcement at crack initiation stage. $F_{r, c r}$ is utilised for detecting if new cracks initiate in next steps of loading. Note that, in the proposed model, the geometric properties of cross-section and reinforcing scheme of the beam is assumed constant over the PBR, and therefore, $F_{r, c r}$ is valid for any other sections of this region. As long as new crack does not form, further increase in rotation prescribed to the extremities may lead to widening of the crack with the consequent increase of sliding in the reinforcing bar $\left(s_{\text {sec. } 1}=w_{r} / 2\right)$. Therefore, the internal force of the reinforcement $\left(F_{r}\right)$ is determined by adding the force due to the strain of the reinforcing $\operatorname{bar}\left(F_{r, \sigma-\varepsilon}\right)$ to the one resulting from sliding of the bar from the surrounding concrete $\left(F_{r, \tau-s}\right)$. The latter is equal to the internal force of reinforcing bar at cracked section (Section 1), which is simulated by $F_{r 1}$ in the approach described in Section 2.2.3.

In the case the flexural beam is made of strain hardening FRCs, due to the enhanced post-cracking characteristic of this type of material, the increase in rotation leads to formation of new micro-cracks [45] as long as $\varepsilon_{e f, r}$ is smaller than $\varepsilon_{c t, p}$, which is the strain corresponding to the tensile peak stress (see Fig. 3a). During the hardening stage, the tensile deformation of the prism is assumed being represented by the strain concept [46]. Hence, the internal force of the reinforcement is solely evaluated from $F_{r, \sigma-\varepsilon}$ during the tensile strain hardening stage of the surrounding FRC. When $\varepsilon_{e f, r}$ exceeds $\varepsilon_{c t, p}$, the critical crack, which is considered to be the one initiated in Section 1, begins to be widened which mobilise the contribution of the post-cracking tensile softening stage of the FRC (Fig. 3b). At this loading stage, the contribution of the term $F_{r, \tau-s}$ due to the occurrence of sliding will be also contributing to the total force of the reinforcing bar. Therefore, for tensile strain hardening FRC, debonding of the reinforcements is only considered for tensile strain higher than $\varepsilon_{c t, p}$, due to the relatively small width of the cracks formed during the tensile strain hardening stage.

Concurrently to the increase of sliding of the reinforcing bar at the first crack (Section 1), the internal force of reinforcement at Section 2 $\left(F_{r 2}\right.$ in Fig. 8a) and the bond transfer length between bar and surrounding concrete $\left(L_{t r}\right)$ increase gradually. The latter is determined by substituting the half the width of crack at Section $1\left(s_{\text {sec. } 1}\right)$ to the corresponding equations represented in Table 1 . In the developed model, it is assumed that the length of beam is long enough to provide an infinite bond transfer length between reinforcing bar and concrete, i.e., $L_{t r}$ remains less than the half-length of the beam.

In each step of computation, the value of $F_{r 2}$ determined from Eq. (17) is compared to $F_{r, c r}$, which was determined previously, in order to verify eventual formation of new crack at Section 2. While $F_{r 2}$ is less than $F_{r, c r}$, the increase in the imposed rotation just leads to the widening of the actual crack at Section 1 accompanied by the increase of the elastic deformation of the intact regions. However, if $F_{r 2}$ attains $F_{r, c r}$, a pair of second cracks (2nd crack in Fig. 8b; due to symmetry only one of these cracks is represented) forms at a distance $L_{t r}^{2 c r}$ from the 1st crack. $L_{t r}^{2 c r}$ is determined by substituting sliding at Section $1\left(s_{\text {sec. } 1}\right)$ into the equations summarised in Table 1 .

From now on and up to the formation of the pair of 3rd cracks, the actual length of the prism $\left(L_{c s}\right)$ is set to $L_{t r}^{2 c r}$. In the new formed prism, the reinforcing bar is tensioned on both sides by widening of the cracks located at the extremities. Therefore, due to equilibrium of the internal forces, the sliding and bond stress tend, necessarily, to zero at a point positioned along the new formed prism. The zero sliding point is assumed to locate at a distance of $k_{L c s}^{m c r} L_{c s}$ from Section 1, where $k_{L c s}^{m c r}$ is a coefficient determined according to the following equation:

$s k_{L c s}^{m c r}=\left\{\begin{array}{lll}0.5 & \left(i f L_{c s} \leqslant 0.5 L_{P B R}\right) & \text { (a) } \\ \frac{L_{S S}}{0.5 L_{P B R}+2 L_{S S}-L_{c s}} & \left(i f L_{c s}>0.5 L_{P B R}\right) & \text { (b) }\end{array}\right.$

where $L_{s s}$ is the length of the beam's shear span (Fig. 7). Note that in Eq. (18), $L_{c s}$ is the actual prism length, which is updated during the proposed computational procedure. Before initiation of the crack $\mathrm{mcr}(\mathrm{mcr}$ is a generic identifier for new pair of cracks, 3cr, $4 \mathrm{cr}$, or $5 \mathrm{cr}$ in Fig. 8), if $L_{c s} \leqslant 0.5 L_{P B R}$ it means that the prism is entirely inside the PBR. In this case, since the widening of the crack and, consequently, sliding of the reinforcing bar at both extremities of the prism are the same, the zero sliding point is located right at midst of the prism and, therefore, by adopting $k_{L c s}^{m c r}$ of 0.5 from Eq. 18a, the length of prism is set to $0.5 L_{c s}$ by the formation crack $m \mathrm{cr}$.

However, when Section 2 is outside the PBR, (i.e. $L_{c s}>0.5 L_{P B R}$ ), the width of the crack at the extremity of the prism outside the PBR is smaller than of the one in Section 1 due to relatively lower bending moment in the adopted four point bending configuration. In this case, sliding of the bar is not equal in the cracks of the extremities of the prism, the wider the crack the larger the sliding. Therefore, the zero sliding point moves toward the extremity located outside the PBR to provide longer transition length in the part corresponding to the crack where a larger sliding occurs (1st crack in Fig. 8b) [47]. In such a case, by assuming a linear correlation between the bond transfer length and bending moment, $k_{L c s}^{m c r}$ is obtained by Eq. $18 \mathrm{~b}$. Therefore, when the third crack forms, the length of the prism is set to $k_{L c s}^{3 c r} L_{c s}$, which is equal to $k_{L c s}^{3 c r} L_{t r}^{2 c r}$ (Fig. 8b). Similarly, once $F_{r 2}$ exceeds $F_{r, c r}$, new pair of cracks is 

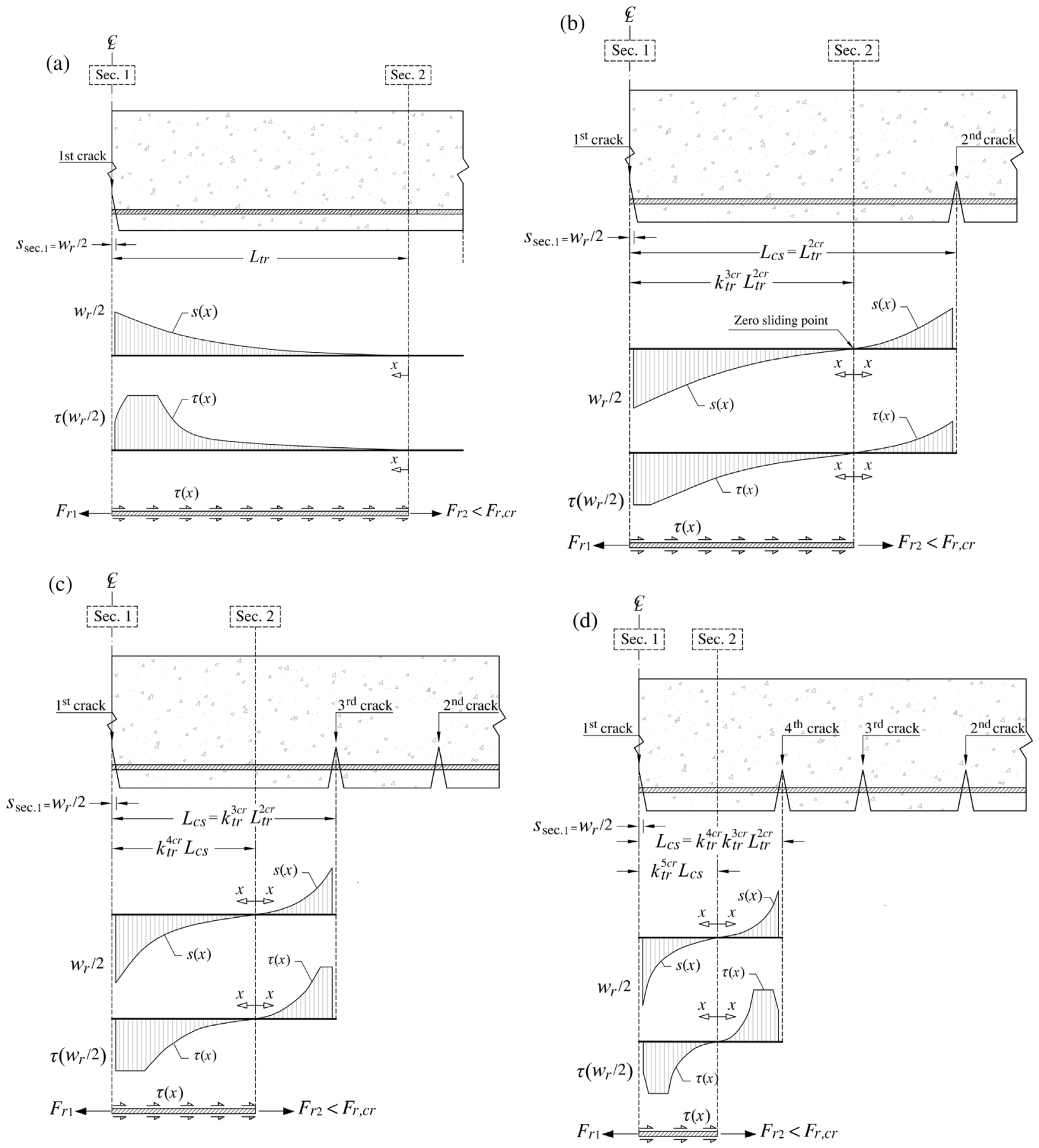

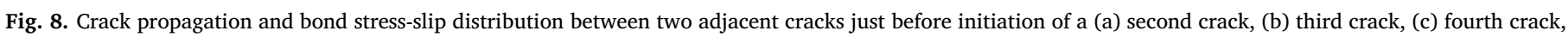
and (d) fifth crack.

detected at the zero sliding point of the prisms. Consequently, as shown in Fig. 8c and d, the distance between cracks is reduced to $k_{L c s}^{4 c r}\left(k_{L c s}^{3 c r} L_{t r}^{2 c r}\right)$ and $k_{L c s}^{5 c r}\left[k_{L c s}^{4 c r}\left(k_{L c s}^{3 c r} L_{t r}^{2 c r}\right)\right]$, when the fourth and the fifth cracks are formed, respectively. The possibility of forming new cracks is successively evaluated, being the minimum crack spacing limited to half the height of cross-section [48].

\section{Algorithm to predict the moment-rotation response of H/FRC element}

In the developed incremental-iterative algorithm, the rotation of the extremities of the PBR of $L_{P B R}$ length in a $k^{\text {th }}$ generic step of the computation is increased by considering a constant increment of $\Delta \theta$ : $\theta^{k}=k \Delta \theta$

Accordingly, the axial elongation of an $i^{\text {th }}$ layer $\left(D_{i}^{k}\right)$ is determined by considering its position along the depth of cross-section $\left(d_{i}\right)$, and depth of the neutral axis $\left(d_{N A}\right.$ in Fig. 1$)$ :

$D_{i}^{k}=\theta^{k}\left(d_{i}-d_{N A}\right)$

It should be noted that $d_{N A}$ is determined iteratively through bisectional approach by satisfying the force equilibrium according to the adopted tolerance of $10 \mathrm{~N}$. The corresponding effective strain of the $\mathrm{PBR}$ is obtained from the following equation: 

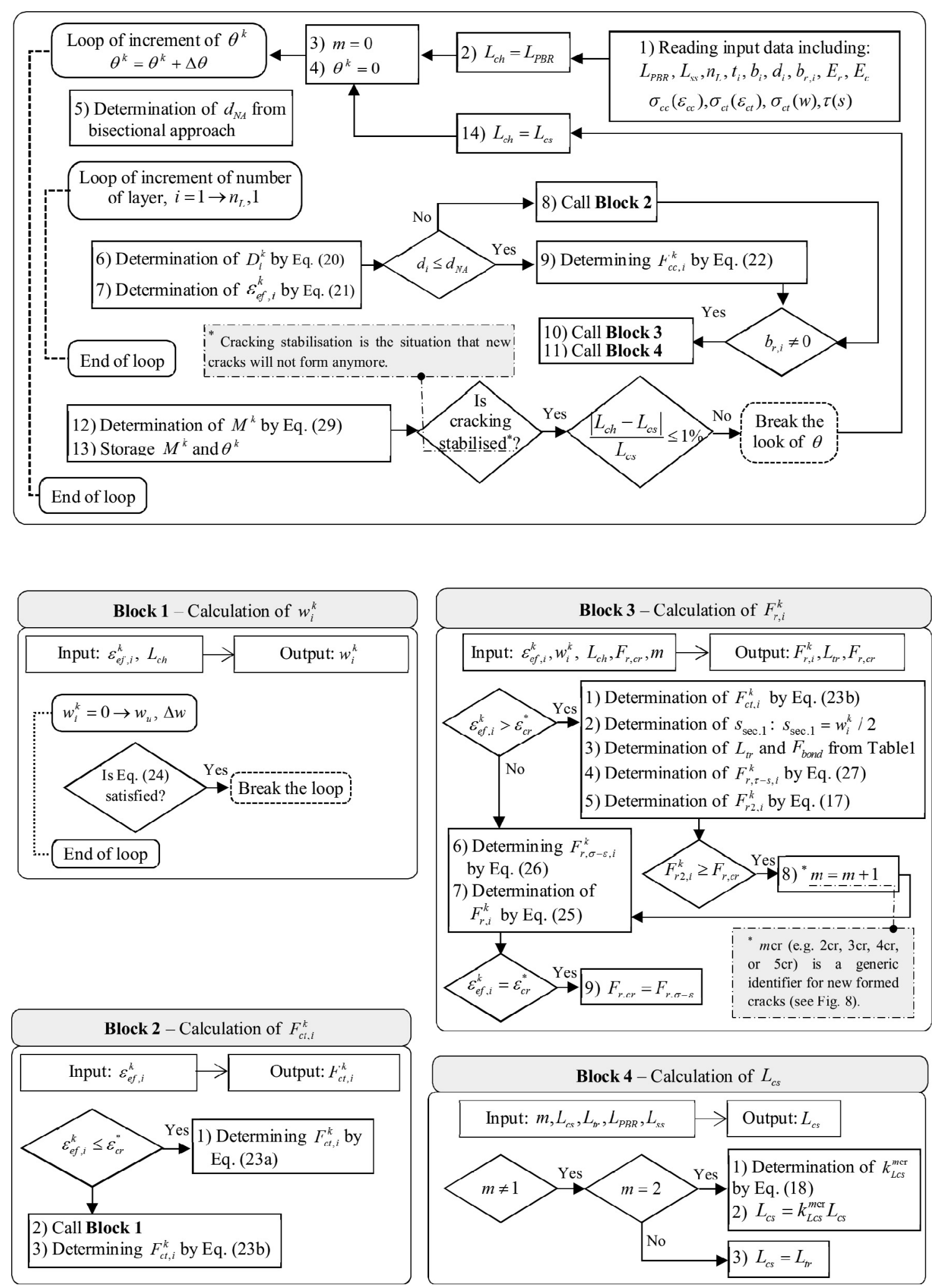

Fig. 9. Flowchart of the algorithm of the model.

$\varepsilon_{e f, i}^{k}=\frac{D_{i}^{k}}{L_{P B R}}$

For the layers located above the neutral axes, where $d_{i}<d_{N A}$, the compressive force of concrete $\left(F_{c c, i}^{k}\right)$ is determined by the following equation:

$$
F_{c c, i}^{k}=\sigma_{c c}\left(\varepsilon_{e f, i}^{k}\right) b_{i} t_{i}
$$

where $\sigma_{c c}\left(\varepsilon_{e f, i}^{k}\right)$ is the compressive constitutive low of concrete depicted in Fig. 2. Tensile force $\left(F_{c t, i}^{k}\right)$ of the layers positioned below the neutral axis $\left(d_{i}>d_{N A}\right)$ is determined by the following equation: 


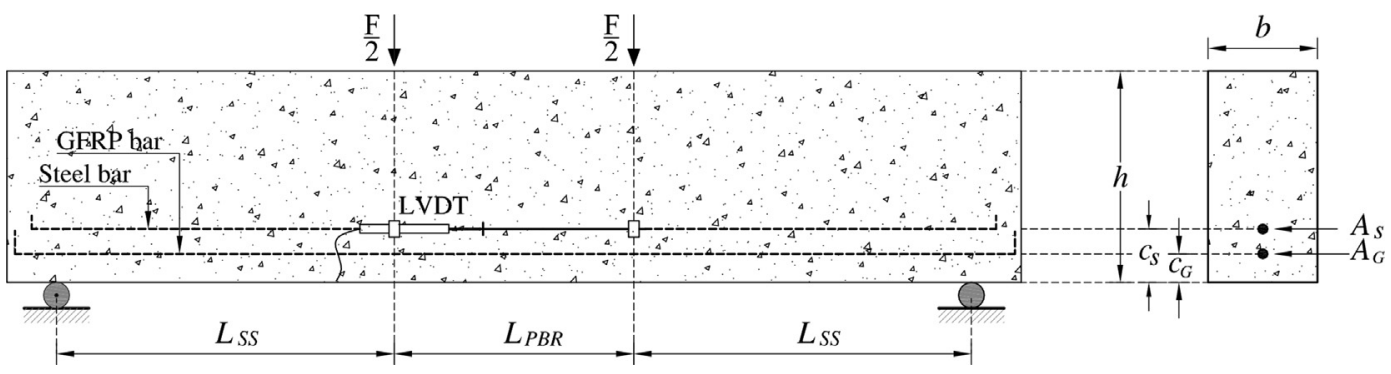

Fig. 10. Four-point bending test setup.

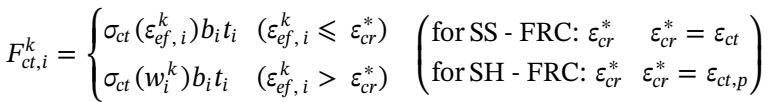

where $\sigma_{c t}\left(\varepsilon_{e f, i}^{k}\right)$ is the pre-cracking (pre-macrocracking localisation in case of SH-FRC) tensile stress of concrete obtained from the constitutive law represented in Fig. 3a, while the crack width of the $i^{\text {th }}$ layer $\left(w_{i}^{k}\right)$ and corresponding post-cracking tensile stress (softening stage) of concrete $\left(\sigma_{c t}\left(w_{i}^{k}\right)\right)$ is obtained by adopting the diagram represented in Fig. 3b.

Considering the effective tensile strain of the layer along a characteristic length of $L_{c h}$ is a superimposition of the equivalent strain due to the average widening of the crack $\left(w_{i}^{k} / L_{c h}\right)$ and the elastic strain of the prism in the vicinity of the crack $\left(\sigma_{c t}\left(w_{i}^{k}\right) / E_{c}\right), w_{i}^{k}$ is determined by solving the following equation through performing an iterative procedure:

$\varepsilon_{e f, i}^{k}-\frac{\sigma_{c t}\left(w_{i}^{k}\right)}{E_{c}}-\frac{w_{i}^{k}}{L_{c h}}=0$

The characteristic length $\left(L_{c h}\right)$ in Eq. (24) is taken equal to the prisms length when cracking is stabilised $\left(s_{r m}\right)$, which is unknown at the beginning of calculation, and should be determine iteratively. For this aim, in the developed model $L_{c h}$ is firstly initiated as the length of PBR $\left(L_{P B R}\right)$, by which the average crack spacing in cracking stabilised stage is obtained through the developed model, to which is attributed the designation $s_{r m}^{1}$. For the second iteration, $L_{c h}=s_{r m}^{1}$ is substituted in Eq. (24), resulting a new value for the average crack spacing $\left(s_{r m}^{2}\right)$. This procedure is repeated up to convergence in terms of $\left(s_{r m}^{k}-s_{r m}^{k-1}\right) / s_{r m}^{k}$ in a certain $k^{\text {th }}$ iteration is attained (a tolerance of $1 \%$ of adopted).

In case the $i^{\text {th }}$ layer includes a longitudinal reinforcing bar, the internal force of the reinforcement $\left(F_{r, i}^{k}\right)$ is a superimposition of the force due to the elongation of reinforcing bar along the $\operatorname{PBR}\left(F_{r, \sigma-\varepsilon, i}^{k}\right)$ and the ones originated from sliding of the bar in the cracked section $\left(F_{r, \tau-s, i}^{k}=F_{r 1, i}^{k}\right)$

$F_{r, i}^{k}=F_{r, \sigma-\varepsilon, i}^{k}+F_{r, \tau-s, i}^{k}$

$F_{r, \sigma-\varepsilon, i}^{k}=b_{r, i} t_{i} \sigma_{r}\left(\varepsilon_{e f, i}^{k}\right)$

$F_{r, \tau-s, i}^{k}=F_{r 1, i}^{k}=n F_{c t, i}^{k}+(n+1) F_{b o n d}$

In Eq. (26), $\sigma_{r}\left(\varepsilon_{e f, i}^{k}\right)$ is the stress of the bar determined regarding the constitutive law schematised in Fig. 4. The intervening parameters in Eq. (27) can be obtained according to the formulation described in Section 2.2.3. If the reinforcement is not crossed by a crack (i.e. $\varepsilon_{e f, i}^{k} \leqslant \varepsilon_{c r}^{*}$ ), a null value is adopted for $F_{r, \tau-s, i}^{k}$ in Eq. (25). Once $\varepsilon_{e f, i}^{k}$ attains $\varepsilon_{c r}^{*}$, value of $F_{r, \sigma-\varepsilon, i}^{k}$ determined by Eq. (26) is allocated to $F_{r, i}^{c r}$ which is representative of force of the reinforcing bar at the $i^{\text {th }}$ layer when the layer is onset by the crack. From now on, $F_{r 1, i}^{k}, F_{r 2, i}^{k}$ and $L_{t r, i}^{k}$ are determined regarding slippage of reinforcement at the crack section by using the formulation described in Section 2.2.3. Once $F_{r 2, i}^{k}$ exceeds $F_{r, i}^{c r}$, a new crack is formed, and the prism length is updated accordingly. For a $i^{\text {th }}$ layer positioned in the compressive zone (i.e. $d_{i}<d_{N A}$ ), Eq. (26) provides a negative value for $F_{r, \sigma-\varepsilon, i}^{k}$, while $F_{r, \tau-s, i}^{k}$ in Eq. (25) is null. It should be remarked that when the cross-section comprises both FRP and steel bars, crack spacing is determined based on steel bar layer. The equilibrium of the axial forces in the cross-section is determined from the following equation:

$\sum F=\sum_{i=1}^{n_{L}^{c}} F_{c c, i}^{k}+\sum_{i=1}^{n_{L}^{t}} F_{c t, i}^{k}+\sum_{i=1}^{n_{L}^{r}} F_{r, i}^{k}$

where $n_{L}^{c}$ and $n_{L}^{t}$ are, respectively, the number of concrete layers positioned in the compressive and tensile zone, and $n_{L}^{r}$ is the number of layers with longitudinal reinforcing bars. When the correct value of the depth of neutral axis $\left(d_{N A}\right)$ is determined for which the equilibrium condition of internal forces is satisfied, the following bending moment of the $k^{\text {th }}$ loading step is determined:

$M^{k}=\sum_{i=1}^{n_{L}^{c}} F_{c c, i}^{k} d_{c c, i}+\sum_{i=1}^{n_{L}^{t}} F_{c t, i}^{k} d_{c t, i}+\sum_{i=1}^{n_{L}^{r}} F_{r, i}^{k} d_{r, i}$

Eqs. (19) and (29) define a point of the moment-rotation relationship $\left(\theta^{k}-M^{k}\right)$. The developed model is described in the flowchart depicted in Fig. 9.

\section{Model appraisal}

The predictive performance of the proposed model was evaluated simulating the moment versus average crack width and estimating the average crack spacing for cracking stabilised stage registered in ten series of R/SFRC beams, designated by B1 to B10, tested experimentally by the authors (B1 to B6, each one including three samples), and tested by other researchers (B7 to B10) under four-point bending configuration, as schematised in Fig. 10. The designation of the SFRC, the geometric properties of the beams, and the beams longitudinal reinforcing schemes are indicated in Table 2. Except B4, B5 and B6, which were hybrid reinforced with a GFRP and a steel bar, the remaining beams were reinforced solely with longitudinal steel bar. The mechanical properties of the reinforcing bars are summarised in Table 3.

In the case of specimens tested in the present research (B1 to B6), the average crack spacing at cracking stabilised stage (when no new more cracks were formed) was determined by dividing the distance between two furthest crack at the level of steel reinforcement in PBR, by the number of uncracked segments between these two cracks. The crack patterns of the tested beams (B1 to B6) are shown in Fig. 11. The average crack width was determined by dividing the deformation of the pure bending region at the steel bar level, measured by the LVDT shown in Fig. 10 mounted at this level, by the total number of cracks that have crossed the concrete at this level. In case of the remaining beams, the values reported in the literature were taken into consideration.

According to Table 2, the beams are made of seven types of SFRCs, designated by SFRC- 1 to -7 , which are distinguished by the concrete strength class and volume content and geometry of hooked-end steel fibres, as detailed in Table 4 . In case of SFRC- 1 to -3 the mean compressive strength at 28 days $\left(f_{c m}\right)$ was obtained by executing uniaxial compressive tests with cylinders according to EN 206-1 [49], while for the SFRC4 to SFRC7 the $f_{c m}$ is the value indicated in the corresponding publication. The tensile strength $\left(f_{c t m}\right)$ and modulus of elasticity $\left(E_{c m}\right)$ of 
Table 2

Geometry and reinforcing scheme of the beams (G represents GFRP; dimensions are in $\mathrm{mm}$ ).

\begin{tabular}{|c|c|c|c|c|c|c|c|c|c|}
\hline \multirow[t]{2}{*}{ Beams series } & \multirow[t]{2}{*}{ SFRC type } & \multicolumn{2}{|c|}{ Geometrical prop. } & \multicolumn{3}{|c|}{ Steel bar } & \multicolumn{3}{|c|}{ GFRP bar } \\
\hline & & $b \times h$ & $L_{S S} / L_{P B R}$ & type & number and diameter $[\mathrm{mm}]$ & $c_{s}[\mathrm{~mm}]$ & type & number and diameter $[\mathrm{mm}]$ & $c_{G}[\mathrm{~mm}]$ \\
\hline B1 & SFRC-1 & $150 \times 100$ & $900 / 500$ & S1 & $1 \Phi 8$ & 40 & - & - & - \\
\hline B2 & SFRC-2 & $150 \times 100$ & $900 / 500$ & S1 & $1 \Phi 8$ & 40 & - & - & - \\
\hline B3 & SFRC-3 & $150 \times 100$ & $900 / 500$ & S1 & $1 \Phi 8$ & 40 & - & - & - \\
\hline B4 & SFRC-1 & $150 \times 100$ & $900 / 500$ & S1 & $1 \Phi 8$ & 40 & G1 & $1 \Phi 8$ & 20 \\
\hline B5 & SFRC-2 & $150 \times 100$ & $900 / 500$ & S1 & $1 \Phi 8$ & 40 & G1 & $1 \Phi 8$ & 20 \\
\hline B6 & SFRC-3 & $150 \times 100$ & $900 / 500$ & S1 & $1 \Phi 8$ & 40 & G1 & $1 \Phi 8$ & 20 \\
\hline B7 [24] & SFRC-4 & $200 \times 350$ & $750 / 1750$ & $\mathrm{~S} 2$ & $2 \Phi 20$ & 45 & - & - & - \\
\hline B8 [25] & SFRC-5 & $100 \times 125$ & $600 / 600$ & S2 & $2 \Phi 10$ & 25 & - & - & - \\
\hline B9 [26] & SFRC-6 & $400 \times 300$ & $900 / 600$ & S3 & $2 \Phi 16$ & 50 & - & - & - \\
\hline B10 [26] & SFRC-7 & $400 \times 300$ & $900 / 600$ & S3 & $2 \Phi 16$ & 50 & - & - & - \\
\hline
\end{tabular}

Table 3

Mechanical properties of the reinforcing bars.

\begin{tabular}{llllll}
\hline Steel/GFRPbar type & $\begin{array}{l}E_{r} \\
{[\mathrm{GPa}]}\end{array}$ & $\begin{array}{l}f_{r y} \\
{[\mathrm{MPa}]}\end{array}$ & $\begin{array}{l}\varepsilon_{r y} \\
{[\% 0]}\end{array}$ & $\begin{array}{l}f_{r u} \\
{[\mathrm{MPa}]}\end{array}$ & $\begin{array}{l}\varepsilon_{r u} \\
{[\% 0]}\end{array}$ \\
\hline S1 & 205 & 575 & 2.8 & 575 & 32 \\
S2 & 200 & 500 & 2.5 & 500 & 15 \\
S3 & 200 & 400 & 2.0 & 400 & 15 \\
$\mathrm{G}^{*}$ & 58 & - & - & 1058 & 18 \\
\hline
\end{tabular}

* Grooved surface.

the SFRCs were determined by Eq. (6) and (7), respectively. In case of SFRCs developed by the authors (i.e. SFRC-1 to -3 ), the post-cracking responses were evaluated by inverse analysis of the force-deflection relationship registered in three-point notched beam bending tests executed according to the recommendations of fib Model Code 2010 [27], a subject that is described in detail in [34].

The adopted post-cracking responses for the SFRC- 6 and -7 , are the ones provided in [26]. In case of SFRC-4 and -5 , however, due to lack of information, the post-cracking response of SFRCs was estimated by following the recommendations of fib Model Code 2010 [27], according to which a linear stress-crack width diagram represented in Fig. 12 is adopted for modelling the FRC in tension.

In this figure $f_{F t s, m}$ and $f_{F t u, m}$ are, respectively, the average serviceability and ultimate residual strength of FRC determined from the following equations:

$f_{F t s, m}=0.45 f_{R 1, m}$

$f_{F t u, m}=f_{F t s, m}-\frac{w_{u}}{C M O D_{3}}\left(f_{F t s, m}-0.5 f_{R 3, m}+0.2 f_{R 1, m}\right) \geqslant 0$

being $f_{R 1, m}$ and $f_{R 3, m}$ the average residual flexural tensile strength of FRC at a CMOD $1=0.5 \mathrm{~mm}$ and $\mathrm{CMOD}_{3}=2.5 \mathrm{~mm}$ evaluated from the force-CMOD relationship determined in three-point notched beam bending tests carried out according to the recommendations of fib Model Code 2010 [27]. In Eq. (31) $w_{u}$ is the ultimate value of crack width that depends on the level of required ductility, which is considered equal to $2.5 \mathrm{~mm}$ for elements failing in bending [27]. Since the flexural residual strength parameters are not available for SFRC-4 and -5 , they were estimated according to the following equations, whose

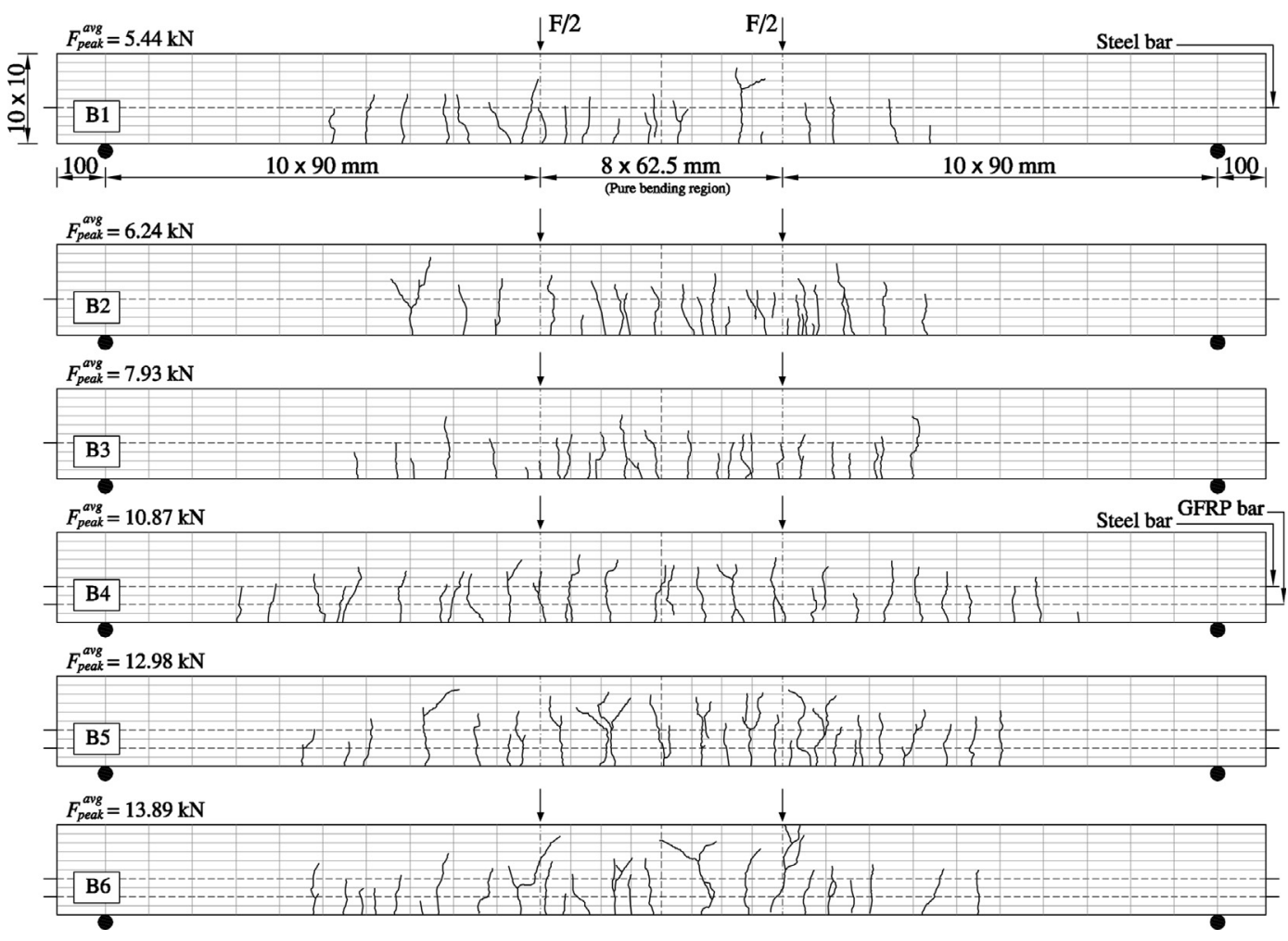

Fig. 11. Typical crack patterns in the tested beams ( $F_{\text {peak }}^{\text {avg }}$ is the average peak load of the corresponding series of beams). 
Table 4

Relevant properties of the used SFRCs.

\begin{tabular}{|c|c|c|c|c|c|c|c|c|}
\hline & & SFRC1 & SFRC2 & SFRC3 & SFRC4 & SFRC5 & SFRC6 & SFRC7 \\
\hline$f_{c m}$ & {$[\mathrm{MPa}]$} & 13.12 & 23.57 & 43.99 & 37.50 & 34.50 & 46.90 & 63.20 \\
\hline$f_{c t m}$ & {$[\mathrm{MPa}]$} & 0.89 & 1.87 & 3.27 & 2.86 & 2.67 & 3.44 & 4.22 \\
\hline$E_{c m}$ & [GPa] & 23.54 & 28.62 & 35.23 & 33.40 & 32.50 & 36.00 & 39.75 \\
\hline$f_{R 1} / f_{R 3}$ & {$[\mathrm{MPa}]$} & $4.02 / 3.20$ & $7.36 / 6.44$ & $11.59 / 9.70$ & $3.52 / 3.10$ & $2.86 / 2.58$ & $5.22 / 4.37$ & $6.27 / 5.13$ \\
\hline$V_{f}$ & [\%] & 0.6 & 0.8 & 1.1 & 0.6 & 0.5 & 1.0 & 1.0 \\
\hline$l_{f}$ & {$[\mathrm{~mm}]$} & 35 & 35 & 35 & 35 & 30 & 35 & 60 \\
\hline$d_{f}$ & {$[\mathrm{~mm}]$} & 0.55 & 0.55 & 0.55 & 0.54 & 0.50 & 0.55 & 0.75 \\
\hline$\alpha_{1}$ & {$[-]$} & 1.90 & 1.45 & 1.35 & 0.55 & 0.48 & 0.62 & 0.49 \\
\hline$\alpha_{2}$ & {$[-]$} & 1.60 & 1.22 & 1.27 & 0.50 & 0.44 & 0.68 & 0.61 \\
\hline$\alpha_{3}$ & {$[-]$} & 1.33 & 0.96 & 1.14 & 0.45 & 0.40 & 0.65 & 0.75 \\
\hline$\alpha_{4}$ & {$[-]$} & 1.00 & 0.69 & 0.87 & 0.40 & 0.35 & 0.33 & 0.76 \\
\hline$\alpha_{5}$ & {$[-]$} & 0.67 & 0.20 & 0.60 & 0.30 & 0.27 & 0.58 & 0.47 \\
\hline$w_{1}$ & {$[\mathrm{~mm}]$} & 0.01 & 0.10 & 0.20 & 0.00 & 0.00 & 0.01 & 0.01 \\
\hline$w_{2}$ & {$[\mathrm{~mm}]$} & 0.20 & 1.00 & 0.50 & 0.50 & 0.50 & 0.11 & 0.05 \\
\hline$w_{3}$ & {$[\mathrm{~mm}]$} & 1.00 & 2.00 & 1.00 & 1.00 & 1.00 & 0.45 & 0.26 \\
\hline$w_{4}$ & {$[\mathrm{~mm}]$} & 2.00 & 3.00 & 2.00 & 1.50 & 1.50 & 0.86 & 0.67 \\
\hline$w_{5}$ & {$[\mathrm{~mm}]$} & 3.00 & 4.90 & 3.00 & 2.50 & 2.50 & 2.78 & 2.32 \\
\hline$w_{u}$ & {$[\mathrm{~mm}]$} & 5.00 & 5.00 & 5.00 & 2.55 & 2.55 & 5.00 & 6.00 \\
\hline
\end{tabular}

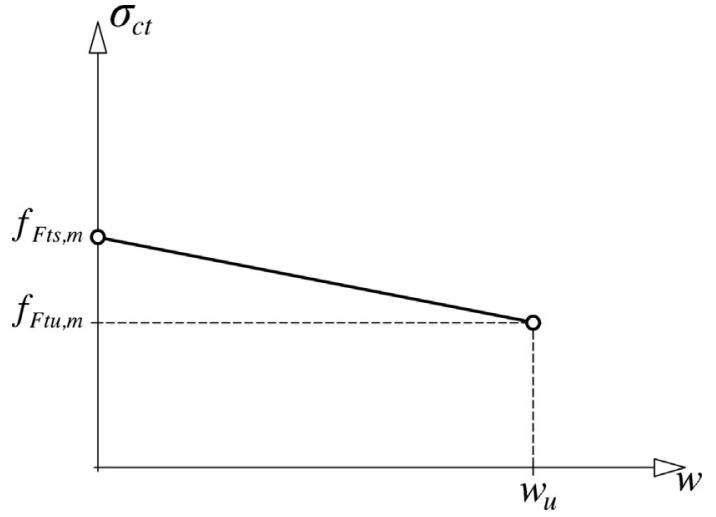

Fig. 12. Tensile stress versus crack opening diagram recommended by fib Model Code 2010 [27].

adequate predictive performance was demonstrated elsewhere [50]:

$f_{R 1, m}=7.5\left(V_{f} l_{f} / d_{f}\right)^{0.8}$

$f_{R 3, m}=6.0\left(V_{f} l_{f} / d_{f}\right)^{0.7}$

being $V_{f}, l_{f}$ and $d_{f}$ the volume percentage, length and diameter of the used fibres, respectively. The values of the parameters that define the local bond-slip constitutive law (Fig. 5) are indicated in Table 5. In case of steel bar, the maximum bond stress $\left(\tau_{\mathrm{m}}\right)$ and corresponding slippage $\left(s_{1}\right)$ (see Fig. 5) were determined by the following equations [51]:

$\tau_{m}=\left[1.77+0.49\left(c_{s} / \phi\right)\right] \sqrt{f_{c m}}$

Table 5

Bond-slip parameters adopted in the simulations.

\begin{tabular}{llllllll}
\hline $\begin{array}{l}\text { Type } \\
\text { of bar }\end{array}$ & SFRC & $\tau_{0}[\mathrm{MPa}]$ & $\tau_{m}[\mathrm{MPa}]$ & $s_{1}[\mathrm{~mm}]$ & $s_{2}[\mathrm{~mm}]$ & $\tau_{R}[\mathrm{MPa}]$ & $s_{3}[\mathrm{~mm}]$ \\
\hline GFRP & SFRC-1 & 1.00 & 12.50 & 0.11 & 1.80 & 5.10 & 7.00 \\
& SFRC-2 & 1.00 & 14.90 & 0.11 & 1.20 & 5.96 & 8.60 \\
& SFRC-3 & 1.00 & 17.30 & 0.11 & 0.60 & 6.92 & 10.20 \\
Steel & SFRC-1 & 0.00 & 16.40 & 0.15 & 2.00 & 6.56 & 5.70 \\
& SFRC-2 & 0.00 & 20.49 & 0.15 & 2.00 & 8.20 & 5.70 \\
& SFRC-3 & 0.00 & 28.13 & 0.15 & 2.00 & 11.25 & 5.70 \\
& SFRC-4 & 0.00 & 14.59 & 0.93 & 2.00 & 5.84 & 15.50 \\
& SFRC-5 & 0.00 & 15.54 & 0.30 & 2.00 & 6.22 & 8.40 \\
& SFRC-6 & 0.00 & 21.56 & 0.38 & 2.00 & 8.62 & 9.60 \\
& SFRC-7 & 0.00 & 25.03 & 0.38 & 2.00 & 10.01 & 9.60 \\
& & & & & & &
\end{tabular}

$s_{1}=c_{0}\left(0.0035 c_{0}+0.006\right)$

where $c_{s}$ is the concrete cover thickness in $\mathrm{mm}, \phi$ is the diameter of the bar in $\mathrm{mm}, f_{\mathrm{cm}}$ is the concrete compressive strength in $\mathrm{MPa}$, and $c_{0}$ is the clear rib spacing of the steel bars and taken equal to 5.7, 6.5, 9.6, and $11.5 \mathrm{~mm}$, respectively, for the $8,10,16$, and $20 \mathrm{~mm}$ diameter bars according to the DIN 488 [52]. Furthermore, regarding the recommendations of fib Model Code 2010 [27], $s_{2}$ and $s_{3}$ are taken equal to $2 \mathrm{~mm}$ and $c_{0}$, respectively, and $\tau_{R}$ is considered $0.4 \tau_{m}$. The values of the parameters that define the local bond-slip relationship of GFRP bar are also included in Table 5. In the case of SFRC- 1 and -2 , these parameters were determined by Pepe et al. [53] by inverse analysis of pull-out bending test results of the same GFRP type and concrete strength class. In case of SFRC-3, however, due to lack of information, the bond-slip constitutive law of the GFRP bar was linearly extrapolated regarding the results presented in [53].

The moment-average crack width relationships predicted by the model are compared with the ones recorded in the experimental programs in Fig. 13. In these figures is also indicated the adopted value of the characteristic length $\left(L_{c h}\right)$ determined by the developed algorithm of Fig. 9. Fig. 13 shows the excellent predictive performance of the developed model.

\section{Predictive performance of available design guidelines}

\subsection{Recommendations of RILEM TC 162-TDF}

According to RILEM TC 162-TDF [33], up to the yield initiation of the steel reinforcement the design value of the crack width $\left(w_{d}\right)$ for R/ FRC members subjected principally to flexure or tension is estimated by the following equation:

$w_{d}=k_{1} s_{r m} \varepsilon_{s m}$

where $k_{1}$ is a coefficient relating the average crack width to the design value, equal to 1.3 or 1.7 depending on the minimum dimension of the cross-section and loading type inducing cracking. In the experimental program composed of beams B1 to B6 (Table 1), since the minimum dimension of the cross-section of these beams $(100 \mathrm{~mm})$ is less than $300 \mathrm{~mm}, k_{1}$ is considered 1.3, which used for converting design value to the average value for comparing the crack width determined by the model to those registered experimentally. In Eq. (36) $s_{r m}$ is the average final crack spacing (at cracked stabilised stage) calculated from the following equation: 

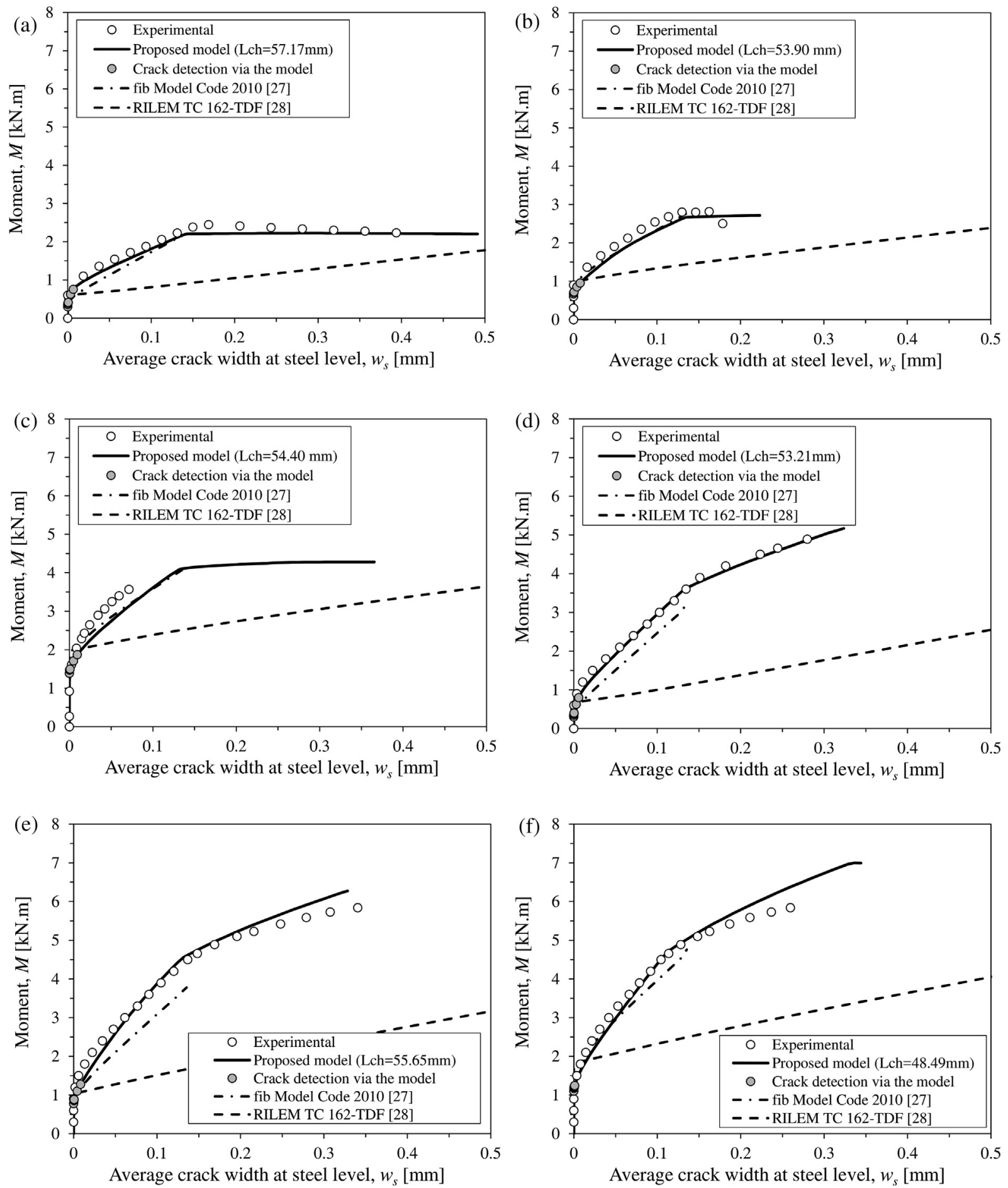

Fig. 13. Predictive performance of the model for the moment-crack width of (a) B1, (b) B2, (c) B3, (d) B4, (e) B5, (f) B6, (g) B7, (h) B8, (i) B9, and (j) B10.

$s_{r m}=\left(50+0.25 k_{2} k_{3} \frac{\phi_{s}}{\rho_{s, e f}}\right)\left(\frac{50}{l_{f} / d_{f}}\right)($ in $\mathrm{mm})$

In this equation $k_{2}$ is a coefficient to take into account the bond properties of the longitudinal bars, equal to 0.8 and 1.6 for the high bond and plain bars, respectively, while $k_{3}$ is a coefficient equal to 0.5 for bending. In Eq. (37) $\phi_{s}$ is the bar diameter, $l_{f} / d_{f}$ is the fibre aspect ratio, being $l_{f}$ and $d_{f}$ the fibre length and diameter, respectively. Furthermore, $\rho_{s, e f}$ is the effective flexural reinforcement ratio determined from the following equation: $\rho_{s, e f}=\frac{A_{s}}{2.5 c_{s} b}$

where $A_{s}$ is the cross-sectional area of the longitudinal reinforcement contained within the effective SFRC area in tension $\left(A_{c, \text { ef }}=2.5 c_{s} b\right)$. In Eq. (36) $\varepsilon_{s m}$ is the average strain in the reinforcement determined from the following equation:

$\varepsilon_{s m}=\frac{\sigma_{s t}}{E_{s}}\left[1-k_{4} k_{5}\left(\frac{\sigma_{s r}}{\sigma_{s t}}\right)^{2}\right]$

where $k_{4}$ is equal to 1.0 and 0.5 for, respectively, high bond and plain 

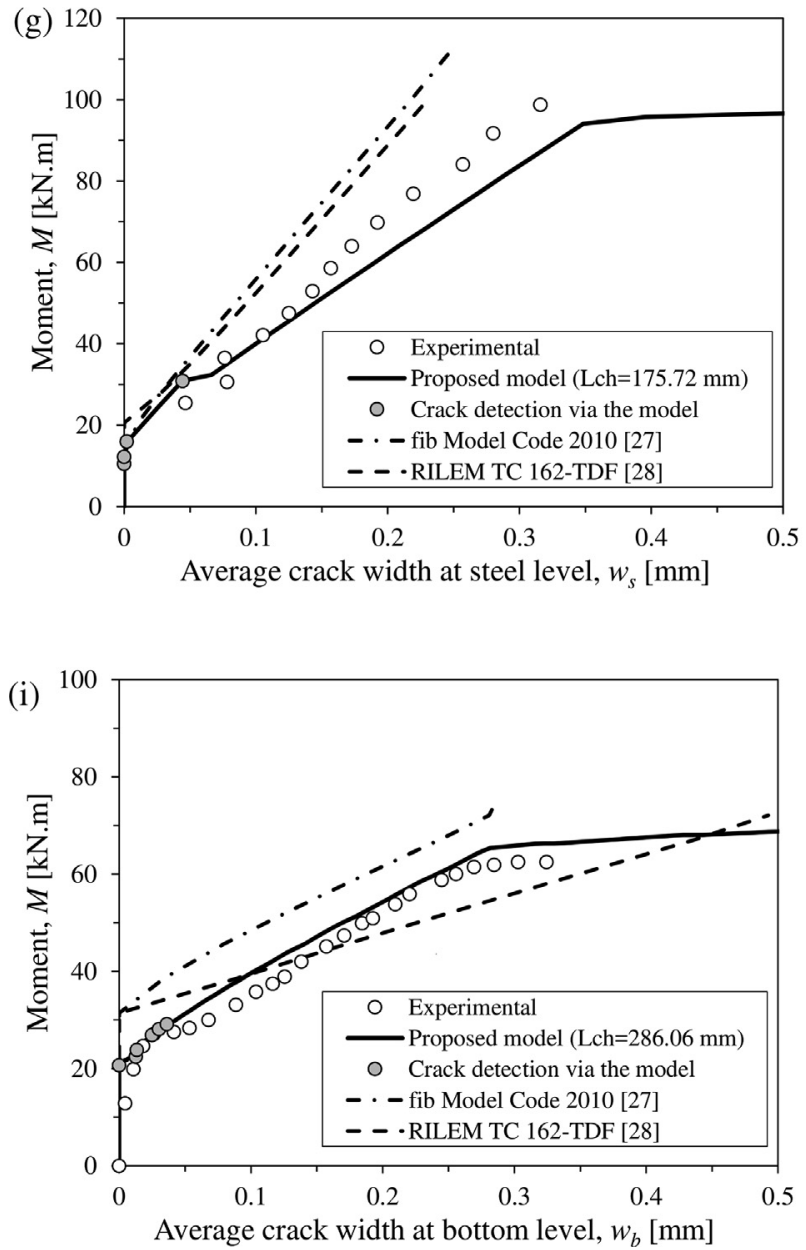
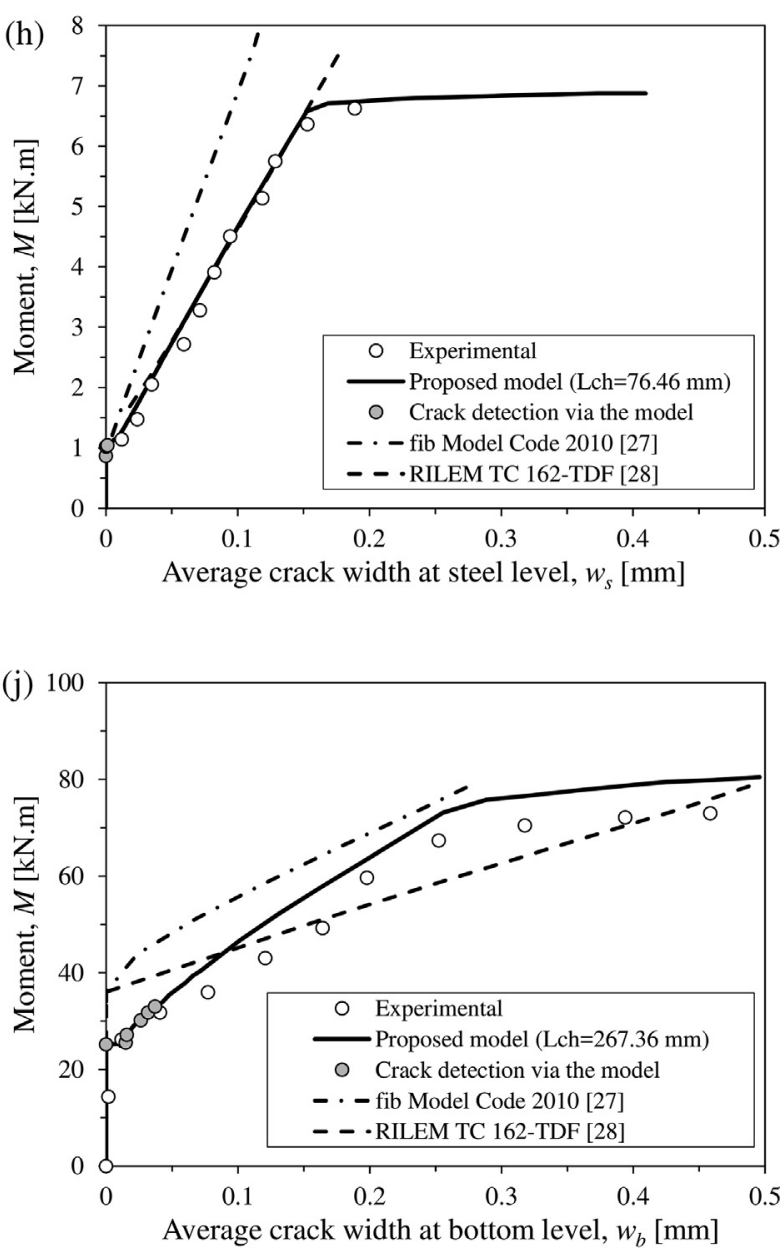

Fig. 13. (continued)

bars, while $k_{5}$ is equal to 1.0 and 0.5 for single, short term loading and for sustained and repeated loading, respectively. In Eq. (39) $\sigma_{s t}\left(=E_{s} \varepsilon_{s}\right)$ is the stress in the steel reinforcement up to the yield initiation, where $\varepsilon_{s}\left(=\chi\left(d_{s}-d_{N A}\right)\right)$ is the strain of the steel reinforcement, being $\chi$ and $d_{N A}$, respectively, the corresponding curvature and the depth of the neutral axes, and $d_{s}$ the depth of this reinforcement. Furthermore $\sigma_{s r}$ is the maximum steel stress at the crack section in the crack formation stage obtained from the following equation:

$\sigma_{s r}=\frac{\left(f_{c t m}-f_{F t s, m}\right)}{\rho_{s, e f}} \cdot\left(1+n_{s} \rho_{s, e f}\right)$

being $n_{s}=E_{s} / E_{c}, f_{c t m}$ is the average value of the tensile strength and $f_{F t s, m}$ is determined by Eq. (30). In the application of this approach the following values were adopted: $k_{1}=1.3 ; k_{2}=0.8 ; k_{3}=0.5 ; k_{4}=k_{5}=1.0$.

\subsection{Recommendations of fib model Code 2010}

According to the fib Model Code 2010 [27] the average crack spacing $\left(s_{r m}\right)$ in R/FRC members is estimated by multiplying by a factor of 1.5 the length over which slip between concrete and steel occurs, which is determined from following equation:

$l_{s, \max }=k_{6} c_{s}+\frac{\left(f_{c t m}-f_{F t s, m}\right)}{4 \tau_{b m}} \frac{\phi_{s}}{\rho_{s, e f f}}$

where $k_{6}$ is an empirical coefficient for simulating the influence of concrete cover thickness that can be assumed equal to 1.0 for the present simulations, and $\tau_{b m}$ is the average bond strength between reinforcing bars and surrounding concrete: $\tau_{b m}=1.8 f_{c t m}$

Eq. (41) is applicable for FRCs when the average residual strength at serviceability limit states $\left(f_{F t s, m}\right)$ is less than the crack strength of concrete matrix $\left(f_{c t m}\right)$. For the other cases $l_{s, \max }=k_{6} c_{s}$ is assumed. Considering the fib Model Code 2010 [27] recommendation, the average crack width $\left(w_{m}\right)$ is determined by dividing the design value of crack width, obtained from Eq. (43), by a factor of 1.7 :

$w_{d}=\frac{2 l_{s, \max }}{E_{s}}\left(\sigma_{s t}-k_{7} \sigma_{s r}-k_{8} \varepsilon_{s h} E_{s}\right)$

In this equation, $\sigma_{s t}$ and $\varepsilon_{s}$ are the stress and strain of steel reinforcement in the cracked section, and $\sigma_{s r}$ is determined by Eq. (40). In the evaluation of the $\sigma_{s t}$ and $\varepsilon_{s}$ the SFRC in tension was considered resisting to a constant value of $f_{F t s, m}$, with a linear stress-strain diagram in the compression zone.

In Eq. (41) $\rho_{s, e f}$ is the effective reinforcement ratio equal to the maximum of $A_{s} /\left(2.5\left(h-d_{s}\right)\right)$ and $A_{s} /\left(\left(h-d_{N A}\right) / 3\right)$, being $h$ the total height of cross-section (see Fig. 7). Furthermore, in Eq. (43) $k_{7}$ is also an empirical coefficient to assess the mean strain over $l_{s, \max }$, considered equal to 0.6 for short-term loading, and $k_{8}$ is a coefficient for considering the shrinkage contribution, which can be considered equal to zero for the short-term loading, and $\varepsilon_{s h}$ is the shrinkage strain.

The predictive performance of the RILEM TC 162-TDF [33] and fib Model Code 2010 [27] approaches is also assessed in Fig. 13 by comparing the moment-average crack width determined by the models and ones registered experimentally. This figure shows that when the RILEM TC 162-TDF [33] was applied to B1 to B6 tested beams, a crack width larger than the one obtained with the other approaches and registered 
Table 6

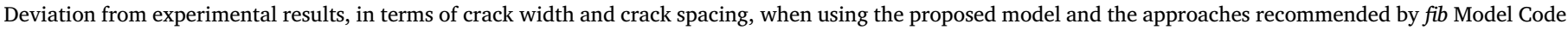
and RILEM (for a bending moment level of $M / M_{\max }^{\exp }=0.8$ ).

\begin{tabular}{|c|c|c|c|c|c|c|c|c|c|}
\hline \multirow[t]{3}{*}{ Beams } & \multirow{3}{*}{$\begin{array}{l}M_{\max }^{\exp } \\
{[\mathrm{kN} \cdot \mathrm{m}]}\end{array}$} & \multicolumn{2}{|c|}{ Experimental } & \multicolumn{2}{|l|}{ Model } & \multicolumn{2}{|c|}{ fib Model Code 2010} & \multicolumn{2}{|l|}{ RILEM } \\
\hline & & $w_{\text {exp }}$ & $L_{c s, \exp }$ & $w_{\text {Model }}$ & $L_{c s, \text { Model }}$ & $w_{f i b}$ & $L_{c s, f i b}$ & $w_{R I L E M}$ & $L_{C S, R I L E M}$ \\
\hline & & {$[\mathrm{mm}]$} & {$[\mathrm{mm}]$} & {$[\mathrm{mm}]$} & {$[\mathrm{mm}]$} & {$[\mathrm{mm}]$} & {$[\mathrm{mm}]$} & {$[\mathrm{mm}]$} & {$[\mathrm{mm}]$} \\
\hline B1 & 2.45 & 0.10 & 82.88 & 0.12 & 57.16 & 0.12 & 60.00 & 0.57 & 226.85 \\
\hline B2 & 2.81 & 0.07 & 76.18 & 0.09 & 53.90 & 0.09 & 60.00 & 0.44 & 226.85 \\
\hline B3 & 3.57 & 0.03 & 81.12 & 0.06 & 54.39 & 0.05 & 60.00 & 0.24 & 226.85 \\
\hline B4 & 4.89 & 0.15 & 68.05 & 0.16 & 53.21 & YL & 60.00 & YL & 226.85 \\
\hline B5 & 5.84 & 0.15 & 67.39 & 0.14 & 55.65 & YL & 60.00 & YL & 226.85 \\
\hline B6 & 6.25 & 0.14 & 54.63 & 0.13 & 48.49 & YL & 60.00 & YL & 226.85 \\
\hline B7 & 97.79 & 0.23 & NA & 0.28 & - & 0.16 & - & 0.11 & - \\
\hline B8 & 6.63 & 0.12 & NA & 0.12 & - & 0.07 & - & 0.12 & - \\
\hline B9 & 62.53 & 0.19 & NA & 0.13 & - & 0.11 & - & 0.23 & - \\
\hline B10 & 73.39 & 0.19 & NA & 0.13 & - & 0.12 & - & 0.25 & - \\
\hline
\end{tabular}

NA: Not available YL: Yielding of steel.

experimentally was estimated. Note that B1 to B6 are the beams made of FRCs whose average residual strength at serviceability limit states $\left(f_{\text {Fts }, m}\right)$ is greater than the crack strength of concrete matrix $\left(f_{\text {ctm }}\right)$. Therefore, the term $f_{\text {ctm }}-f_{F t s, m}$ in Eq. (40) is taken null, which means $\sigma_{s r}=0$. In case of B7, B9 and B10, however, RILEM approach has predicted satisfactorily the test results. In particular, predictive performance of this approach is excellent in case of B8. These beams are made of FRCs for which $f_{F t s, m}$ is smaller than $f_{c t m}$ and, accordingly, a non-zero value of term $f_{c t m}-f_{F t s, m}$ is utilised in Eq. (40).

The fib Model Code 2010 [27] approach predicted generally acceptable crack width versus applied bending moment response in case of B1 to B6, where $f_{c t m}-f_{F t s, m}$ of zero is used in Eq. (41), i.e. $l_{s, \max }=k_{6} c_{s}$. However, relative larger crack width is determined by the fib approach for the hybrid reinforced beams (i.e. B4 to B6).

In case of B7 to B10, a relative smaller average crack width was obtained with the fib Model Code 2010 [27] approach, where a nonzero value of term $f_{c t m}-f_{F t s, m}$ is utilised. This means that the contribution of the post-cracking of FRC in the fib Model Code 2010 [27] formulation is overestimated.

Table 6 compares the average crack width registered experimentally and predicted by the fib and RILEM approaches, as well as the proposed model, at a bending moment of $80 \%$ of the maximum moment recorded experimentally, at which cracking was verified to be stabilised (no new more cracks are formed).

If beam B3 is excluded, deviation of the prediction of the proposed model in terms of crack width $\left(\right.$ Error $\left.{ }^{\text {Model }}=\left|w_{\text {exp }}-w_{\text {Model }}\right| / w_{\text {exp }}\right)$ varies between 0 and 32\%, whereas fib Model Code 2010 approach resulted in a larger error, ranging between $20 \%$ and $42 \%$. When using the RILEM approach, deviation is between 0 and $529 \%$. Note that in case of B4 to B6 beams, at the bending moment of $80 \%$ of the flexural capacity of these beams $\left(M / M_{\max }^{\exp }=0.8\right)$ the steel bar has already yielded, therefore the fib Model Code 2010 and RILEM approaches are not capable of predicting the crack width at this yielding stage. It is notable that in case of B3 beam, although the model prediction of crack width is about two times the one registered in the experimental test, the other two approaches have also provided the highest deviations (i.e. $67 \%$ and $700 \%$ in case of fib and RILEM approaches, respectively), suggesting an eventual error on the experimental measuring process of the average crack width in this beam. Regarding Table 6, for the considered $M / M_{\max }^{\exp }=0.8$, the model predicted the crack spacing in the tested beams (B1 to B6) with a deviation (Error $\left.^{\text {Model }}=\left|L_{c s, \exp }-L_{c s, \text { Model }}\right| / L_{c s, \exp }\right)$ of $11 \%$ to $33 \%$ when compared with the experimental results, while the approaches recommended by the fib Model Code 2010 and RILEM resulted in errors of $10 \%$ to $27 \%$ and $174 \%$ to $315 \%$, respectively.

\section{Conclusions}

In the present paper, a new model was developed based on the moment-rotation response of FRC elements reinforced flexurally with conventional steel and/or FRP bars, which were designated by R/FRC members. The model considers the constitutive laws of FRC in compression and tension, as well as the bond-slip behaviour between flexural reinforcement and surrounding FRC to predict the cracking behaviour of R/FRC elements failing in bending. The predictive performance of the proposed model was assessed simulating experimental tests conducted on R/FRC beams of different geometry, FRC material properties, and flexural reinforcing schemes, including the ones executed by the authors in a parallel research, as well as some experimental tests reported in the literature. The model has predicted with high accuracy the moment- average crack width and the average crack spacing at cracking stabilised stage. This predictive performance was better than the ones obtained by applying the approaches recommended by RILEM TC 162-TDF and fib Model Code 2010.

\section{CRediT authorship contribution statement}

Mahsa Taheri: Conceptualization, Methodology, Software, Validation, Investigation, Writing - original draft, Writing - review \& editing. Joaquim A.O. Barros: Conceptualization, Methodology, Resources, Supervision, Writing - review \& editing. Hamidreza Salehian: Methodology, Investigation, Software, Writing - original draft.

\section{Acknowledgements}

The authors acknowledge the support provided by the project ICOSytec, project number 027990, Announcement 02/SAICT/2017, financed by FCT (Protuguese Foundation for Science and Technology) and co-funded by FEDER through Operational Competitiveness and Internationalization Programme (POCI)

\section{References}

[1] Arya C, Wood LA. The relevance of cracking in concrete to reinforcement corrosion. 2nd ed. The Concrete Society; 2015.

[2] Wang H, Belarbi A. Flexural durability of FRP bars embedded in fiber-reinforcedconcrete. Constr Build Mater 2013;44:541-50.

[3] Abdalla HA. Evaluation of deflection in concrete members reinforced with fibre reinforced polymer (FRP) bars. Compos Struct 2002;56:63-71.

[4] Almusallam TH. Analytical prediction of flexural behavior of concrete beams reinforced by FRP bars. J Compos Mater 1997;31:640-57.

[5] Masmoudi R, Theriault M, Benmokrane B. Flexural behavior of concrete beams reinforced with deformed fiber reinforced plastic reinforcing rods. Struct J 1998;95.

[6] ACI 440R-07. Report on fibre-reinforced polymer (FRP) reinforcement for concrete 
structures. American Concrete Institute, ACI Committee 440; 2007. p. 100

[7] Aiello MA, Ombres L. Structural performances of concrete beams with hybrid (fiberreinforced polymer-steel) reinforcements. J Compos Constr 2002;6:133-40.

[8] Tian Y, Yuan Y. Deflection prediction of concrete beams reinforced with GFRP and steel rods. In: The 8th international symposium on fiber reinforced polymer reinforcement for concrete structures (FRPRCS-8). Patras, Greece; 2007.

[9] Naaman AE. Fiber reinforcement for concrete: looking back, looking ahead. In: Rossi P, Chanvillard G, editors. Proceedings of fifth RILEM symposium on fiber reinforced concretes (BEFIB2000). Rilem Publications, S.A.R.L.; 2000. p. 65-86.

[10] Barros JAO, Cunha VMCF, Ribeiro AF, Antunes JAB. Post-cracking behaviour of steel fibre reinforced concrete. Mater Struct 2005;38:47-56.

[11] Santos PFS, Barros JAO, Lourenço LAP. Steel fibres for the shear resistance of high strength concrete beams. In: Gettu R, editor. 7th RILEM international symposium on fibre reinforced concrete design and applications (BEFIB 2008). Chennai, India; 2008.

[12] Barros JAO, Gettu R, Barragan BE. Material nonlinear analysis of steel fibre reinforced concrete beams failing in shear. In: BEFIB2004 conference. Varenna, Lake Como, Italy; 2004. p. 711-20.

[13] Susetyo J, Gauvreau P, Vecchio FJ. Effectiveness of steel fiber as minimum shear reinforcement. Struct J 2011:108.

[14] Casanova P, Rossi P, Schaller I. Can steel fibers replace transverse reinforcements in reinforced concrete beams? Mater J. 1997;94:341-54.

[15] Taheri M, Barros JAO, Salehian H. A design model for strain-softening and strainhardening fiber reinforced elements reinforced longitudinally with steel and FRP bars. Compos B Eng 2011;42:1630-40.

[16] Barros JAO, Taheri M, Salehian H, Mendes PJD. A design model for fibre reinforced concrete beams pre-stressed with steel and FRP bars. Compos Struct 2012;94:2494-512.

[17] Abrishami H, Mitchell D. Influence of steel fibers on tension stiffening. Struct J 1997;94.

[18] Lee S-C, Cho J-Y, Vecchio FJ. Tension-stiffening model for steel fiber-reinforced concrete containing conventional reinforcement. ACI Struct J 2013.

[19] Bischoff PH. Tension stiffening and cracking of steel fiber-reinforced concrete. J Mater Civ Eng 2003;15:174-82.

[20] Oliveira Júnior L, Lima Araújo D, Dias Toledo Filho R, Moraes Rego Fairbairn E, Souza de Andrade M. Tension stiffening of steel-fiber-reinforced concrete. Acta Scientiarum Technol 2016;38:456-63.

[21] Chiaia B, Fantilli AP, Vallini P. Evaluation of crack width in FRC structures and application to tunnel linings. Mater Struct 2008;42:339-51.

[22] Jordon RD, Frank JV. Cracking behavior of steel fiber-reinforced concrete members containing conventional reinforcement. Struct J 2013;110.

[23] Taheri M, Barros JAO. An analytical model to simulate tension stiffening mechanism in moment-rotation response of FRC flexural members with tensile long itudinal reinforcement. Guimaraes, Portugal: University of Minho; 2012. p. 34.

[24] Vandewalle L. Cracking behaviour of concrete beams reinforced with a combination of ordinary reinforcement and steel fibers. Mater Struct 2000;33:164-70.

[25] Tan K-H, Paramasivam P, Tan K-C. Cracking characteristics of reinforced steel fiber concrete beams under short- and long-term loadings. Adv Cem Based Mater 1995;2:127-37.

[26] Montaignac R, Massicotte B, Charron J-P. Design of SFRC structural elements: flexural behaviour prediction. Mater Struct 2012;45:623-36.

[27] fib Model Code 2010. CEB and FIP - Final Draft; 2011.

[28] RILEM TC 162-TDF. Test and design methods for steel fibre reinforced concrete, $\sigma-\varepsilon$ design method - final recommendation. Mater Struct 2003;36:560-7.

[29] Van Mier JGM. Fracture Processes of Concrete. CRC Press; 1997.

[30] Barros JAO, Taheri M, Salehian H. A model to simulate the moment-rotation and crack width of FRC members reinforced with longitudinal bars. Eng Struct 2015;100:43-56.
[31] Vipulanandan C, Paul E. Performance of epoxy and polyester polymer concrete. ACI Mater J 1990;87:241-51.

[32] Barros JAO, Figueiras JA. Flexural behaviour of steel fibre reinforced concrete: testing and modelling. ASCE Mater Civil Eng J 1999;11:331-9.

[33] Vandewalle Nemegeer, Balazs Barr, Barros Bartos, Banthia Criswell, Denarié di Prisco, Falkner Gettu, Gopalaratnam Groth, Häusler Kooiman, Kovler Massicotte, Mindess Reinhardt, Rossi Schaerlaekens, Schumacher Schnütgen, Shah Skarendahl, Stang Stroeven, Swamy Tatnall, Teutsch,Walraven. RILEM TC 162-TDF: test and design methods for steel fibre reinforced concrete, $\sigma-\varepsilon$ design method - final recommendation. Mater Struct 2003;36:560-7.

[34] Salehian H. Evaluation of the performance of steel fibre reinforced self-compacting concrete in elevated slab systems; from the material to the structure. University of Minho; 2015.

[35] Pereira EB, Fischer G, Barros JAO. Direct assessment of tensile stress-crack opening behavior of Strain Hardening Cementitious Composites (SHCC). Cem Concr Res 2012;42:834-46.

[36] Salehian H, Barros JAO. Assessment of the performance of steel fibre reinforced selfcompacting concrete in elevated slabs. Cem Concr Compos 2015;55:268-80.

[37] Barros JAO, Pereira E, Santos S. Lightweight panels of steel fiber-reinforced selfcompacting concrete. J Mater Civ Eng 2007;19:295-304.

[38] Baena M, Torres L, Turon A, Barris C. Experimental study of bond behaviour between concrete and FRP bars using a pull-out test. Compos B Eng 2009;40:784-97.

[39] Harajli M, Hamad B, Karam K. Bond-slip response of reinforcing bars embedded in plain and fiber concrete. J Mater Civ Eng 2002;14:503-11.

[40] Eligehausen R, Popov EP, Bertero VV. Local bond stress-slip relationships of deformed bars under generalized excitations; 1982.

[41] Bianco V, Barros JA, Monti G. Bond model of NSM-FRP strips in the context of the shear strengthening of RC beams. J Struct Eng 2009;135:619-31.

[42] Barros JAO, Foster SJ. An integrated approach for predicting the shear capacity of fibre reinforced concrete beams. Eng Struct 2018;174:346-57.

[43] Conforti A, Minelli F, Plizzari GA. Wide-shallow beams with and without steel fibres: a peculiar behaviour in shear and flexure. Compos B Eng 2013;51:282-90.

[44] Ortiz Navas F, Navarro-Gregori J, Leiva Herdocia G, Serna P, Cuenca E. An experimental study on the shear behaviour of reinforced concrete beams with macrosynthetic fibres. Constr Build Mater 2018;169:888-99.

[45] Naaman AE. Strain hardening and deflection hardening fiber reinforced cement composites. RILEM Publications; 2003.

[46] Naaman AE. High performance fiber reinforced cement composites. In: Shi C, Mo YL, editors. High-performance construction materials - science and applications. World Scientific Publishing Co. Pte. Ltd.; 2008.

[47] Piyasena R. Crack spacing, crack width and tension stiffening effect in reinfroced concrete beams andone-way slabs. Griffith University; 2002.

[48] Massicotte B. Implementing SFRC design into North American codes: application to a building floor. Invited paper to the International workshop on the advanced in fibre reinforced concrete. Bergamo, Italy; 2004. p. 73-80.

[49] EN 206-1. Concrete - Part 1: Specification, performance, production and conformity, vol. 69; 2000.

[50] Moraes-Neto BN, Barros JAO, Melo GSSA. A model for the prediction of the punching resistance of steel fibre reinforced concrete slabs centrically loaded. Constr Build Mater 2013;46:211-23.

[51] Desnerck P, De Schutter G, Taerwe L. A local bond stress-slip model for reinfrocing bars in self-compacting concrete. In: $\mathrm{Oh} \mathrm{BH}$, editor. Fracture mechanics of concrete and concrete structures - assessment, durability, monitoring and retrofitting of concrete structures Seoul, Korea; 2010.

[52] DIN 488. Germany Standard Ribbed steel bars; 1986.

[53] Pepe M, Mazaheripour H, Barros J, Sena-Cruz J, Martinelli E. Numerical calibration of bond law for GFRP bars embedded in steel fibre-reinforced self-compacting concrete. Compos B Eng 2013;50:403-12. 